\title{
PERPETUAL SHIFT
}

\author{
PAUL ALOISI \\ Bachelor of Design, OCAD University, 2003
}

\begin{abstract}
A Major Research Project presented to Ryerson University in partial fulfilment of the requirements for the degree of Master of Digital Media in the program of Digital Media
\end{abstract}

Toronto, Ontario, Canada, 2018

(C) Paul Aloisi, 2018 


\section{AUTHOR'S DECLARATION FOR ELECTRONIC SUBMISSION OF AN MRP}

I hereby declare that I am the sole author of this MRP. This is a true copy of the MRP, including any required final revisions.

I authorize Ryerson University to lend this MRP to other institutions or individuals for the purpose of scholarly research.

I further authorize Ryerson University to reproduce this MRP by photocopying or by other means, in total or in part, at the request of other institutions or individuals for the purpose of scholarly research.

I understand that my MRP may be made electronically available to the public. 


\author{
PERPETUAL SHIFT \\ Paul Aloisi, 2018 \\ Master of Digital Media \\ Digital Media \\ Ryerson University, 2018
}

\begin{abstract}
Perpetual Shift, a responsive art installation, exists at the intersection of digital media, art and architecture, bearing a range of connections to the realm of ubiquitous computing and adding to evolving perspectives in the fields of installation art and interactive architecture by proposing a new mode of engaging with data through the physical built environment. The physical embodiment of the sculpture has the functional properties of a Tangible User Interface and employs an innovative approach to material application to generate multi-modal dynamic output (sight and sound). Though as a device Perpetual Shift is capable of being programmed to function as a form of data-physicalization, this artwork is a form of data-sculpture whereby location of the human body is interpreted as data which drives the actuation of the built environment.
\end{abstract}




\section{ACKNOWLEDGEMENTS}

I would like to acknowledge the work of those who came before me and the inspiration which they have provided. 


\section{TABLE OF CONTENTS}

AUTHOR'S DECLARATION

$\begin{array}{lll}\text { ABSTRACT } & \text { iii }\end{array}$

ACKNOWLEDGEMENTS

LIST OF TABLES vi vi

LIST OF PLATES Vii

LIST OF FIGURES V viii

LIST OF APPENDICES $\quad$ ix

1. INTRODUCTION

2. CONCEPTUAL APPROACH 2

3. LITERATURE REVIEW 4

4. PERPETUAL SHIFT: INFORMATION INTERFACE 19

5. PERPETUAL SHIFT: PHYSICAL DESCRIPTION 20

6. PERPETUAL SHIFT: EXPERIENTIAL DESCRIPTION 24

7. PERPETUAL SHIFT: EXTENDED COMMUNICATIVE QUALITIES 30

8. PERPETUAL SHIFT: FUTURE DEVELOPMENT 32

9. CONCLUSION 33

$\begin{array}{ll}\text { APPENDICES } & 34\end{array}$

$\begin{array}{ll}\text { REFERENCES } & 40\end{array}$ 


\section{LIST OF TABLES}

Table 01. Aloisi, P. (2018) Perpetual Shift: Framework of Interaction 


\section{LIST OF PLATES}

Plate 01. Price, C. (1961). Fun Palace. 04

Plate 02. - Frazer, J. (1993). Interactive Skin. 05

Plate 03. - Adekola, A. (1992). Interactive output device for displaying an emotional state. 05

Plate 04. - AHR. (2012). Al-Bahar Towers, Abu Dhabi. 11

Plate 05. - AHR.(2012). Al-Bahar Towers, Abu Dhabi. 11

Plate 06. - Aloisi, P. (2018) Perpetual Shift: Panel Reflection 23

Plate 07. - Aloisi, P. (2018) Perpetual Shift: Installation Bird's Eye Perspective Rendering 26

Plate 08. - Aloisi, P. (2018) Perpetual Shift: Zone 0

Plate 09. - Aloisi, P. (2018) Perpetual Shift: Zone 1

Plate 10. - Aloisi, P. (2018) Perpetual Shift: Zone 2

Plate 11. - Aloisi, P. (2018) Perpetual Shift: Zone 3

Plate 12. - Aloisi, P. (2018) Perpetual Shift: Zone 3

Plate 13. - Aloisi, P. (2018) Perpetual Shift: Zone 4

Plate 14. - Aloisi, P. (2018) Perpetual Shift: Zone 5 


\section{LIST OF FIGURES}

Figure 01. - Aloisi, P. (2018) Perpetual Shift: Idealized Plan of Installation Venue 20

Figure 02. - Aloisi, P. (2018) Perpetual Shift: Installation Plan 21

Figure 03. - Aloisi, P. (2018) Perpetual Shift: Installation Section 1

Figure 04. - Aloisi, P. (2018) Perpetual Shift: Interior Elevation 22

Figure 05. - Aloisi, P. (2018) Perpetual Shift: Modular Segment Details 23

Figure 06. - Aloisi, P. (2018) Perpetual Shift: Panel Detail 23

Figure 07. - Aloisi, P. (2018) Perpetual Shift: Framework of Interaction Schematic 25 


\section{LIST OF APPENDICES}

Appendix 01. - Documentation of Iterative Design Process 


\section{INTRODUCTION}

Ubiquitous computing, the seamless integration of computational systems into the built environment and the artifacts therein, has the capacity to alter our experience and perception of space. Furthermore, context-aware computing (Schilit \& Theimer, 1994) which permits localized data collection and analysis can offer enhanced personalization of our experience of the built environment. This document describes the conceptual underpinnings of Perpetual Shift, a responsive art installation which establishes conditions in which a person's physcial location in space results in an atmospheric transformation of the built environment, thereby altering one's perception of it and experience within it. The primary intent behind the creation of this artwork is to promote critical reflection on the impacts that the pervasive presence of digital media is having on contemporary societal conditions. More narrowly, by making reference to contemporary installation art and architectural facades, the direction of this artistic inquiry explores dynamic architectonic surfaces as communicative interfaces between people and the built environment we inhabit and investigates how built form may become imbued with an influential expressive capacity?

Architecture offers much more than shelter and protection from the elements, equally importantly "it provides a context for human experiences" (Eberhard, 2009. p.753). Contrasts of interior and exterior, public and private, are fundamental to a contemplation of the urban built environment. Not only do architectural facades contain and shield interior, private space, they form experiential context for human activity outdoors in the public realm and act as a building's interface with the city. As an interface, "something that is between two other parts or systems, and helps them communicate or interact with one another" (de Souza \& Frith, 2012. p.2), a facade can be considered a medium capable of conveying some form of information. Historically the composition of an architectural facade has passively conveyed information about a building's 
means of construction, the proportions of its internal structural system and the functional relationship between programmatic elements of its interior while simultaneously outwardly positing ambient effects which demonstrate an autonomous connection to the urban context in which the building exists. The communcative language of traditional static architecture employs materiality, proportion, and patterns of solid or void, form or volume as means of expression.

From approximately the mid $20^{\text {th }}$ century to present day this distinct connection between the internal functional aspects of a building, its structure, and the surface of its building envelope has gradually eroded. In contemporary architecture the skin of a building often becomes structurally and conceptually disjointed from it's internal physical framework and functional purpose; "the properties of a building's surface... are not superficial; they construct the spatial effects by which architecture communicates. Through its surfaces a building declares both its autonomy and its participation in its surroundings" (Leatherbarrow \& Mostavi, 2002, preface). Perpetual Shift aims to celebrate this surface condition and position it as a communicative tool

for the dynamic transmission of information between people and the built environment. Through the dynamic communicative potential of contemporary facades, architecture's function as a medium for social engagement is also enhanced, contributing to the possibility of an enriched framing of human experience. By employing data relating to human activity captured in the immediate area of the art installation as unique variables, this work bolsters the argument for user specificity and intends to reinforce the importance of the relationship between communicative content and the context in which it is situated.

\section{CONCEPTUAL APPROACH}

I have approached the development and production of this artwork from the perspective that "art itself may be understood as product of human need to remake the world in search of 
deeper understanding" (Glynn, 2016, pp.1). The outcome of this directive is the conceptualization, technical design, and prototyping of a work which speculates about the implications of ubiquitous computing on contemporary experiences of the built environment through a responsive art installation employing digital fabrication and physical computing techniques. With this work I do not aim to propose a solution to any fixed problem but to conceive of an environment where visitors can experience the influence their presence may have over an environment and additionally the influence a responsive environment may have over their embodied human experience. Perpetual Shift is a critical artwork which bears significant conceptual relationships with contemporary societal conditions resultant from the application of technical developments in digital media, including:

- Location Aware Technologies, Automation, Internet of Things

- Persuasive/Coercive Environments, Behaviour Tracking/Prediction

- The Attention Economy, Commodification of Human Engagement

- Surveillance, Data collection, Privacy

- Addictive by Design, Likes, Selfie Culture

- Code Author Bias, Dark Pattern, Black Box

This project proposes a reactive environment where human presence and engagement with the sculptural elements results directly in altered ambient conditions. Sensors integrated into the artwork will track activity within the installation zone and will trigger numerous actuators to respond dynamically based on a relationship encoded into the systems' processing microcontroller. As people explore the causal relationship of their behaviour and the reaction of the built environment, it also becomes plausible for them to intentionally control environmental conditions, resulting in the transformation of object and environment into performative instrument. Applied inversely, this anticipates prospective near-future scenarios where environments enhanced by ubiquitous computing may dynamically enact coercive conditions upon users based on possessing an awareness of human presence and layers of data specific to individual members of society. 


\section{LITERATURE REVIEW}

Responsiveness, interactivity and adaptation as concepts applied in the built environment are rooted in ideas emergent in the early 1960's and which continue to evolve to this day. Perpetual Shift contributes to the dialog in this realm which is influenced by an interdisciplinary range of thinkers.

Foundational scientific work by Norbert Weiner in the field of Cybernetics, which he describes as "control and communication in the animal and the machine" (Wiener, 1948), proved inspirational to many intellectuals and creatives after him and his work is widely referenced as a point of origin. Wiener proposed that electronic interfaces would offer humans expanded control over the built environment (Nabian \& Ratti, 2017, pp.6).

In the field of architecture, British practitioner Cedric Price developed early experimental architectural concepts exploring cybernetic systems, notably The Fun Palace (1961) which would theoretically apply movement, adaptation and change to the built environment so as to respond to the requirements of it visitors. Although these works were never constructed, the ideas therein stimulated others to examine the potential of a dynamically changing built environment.

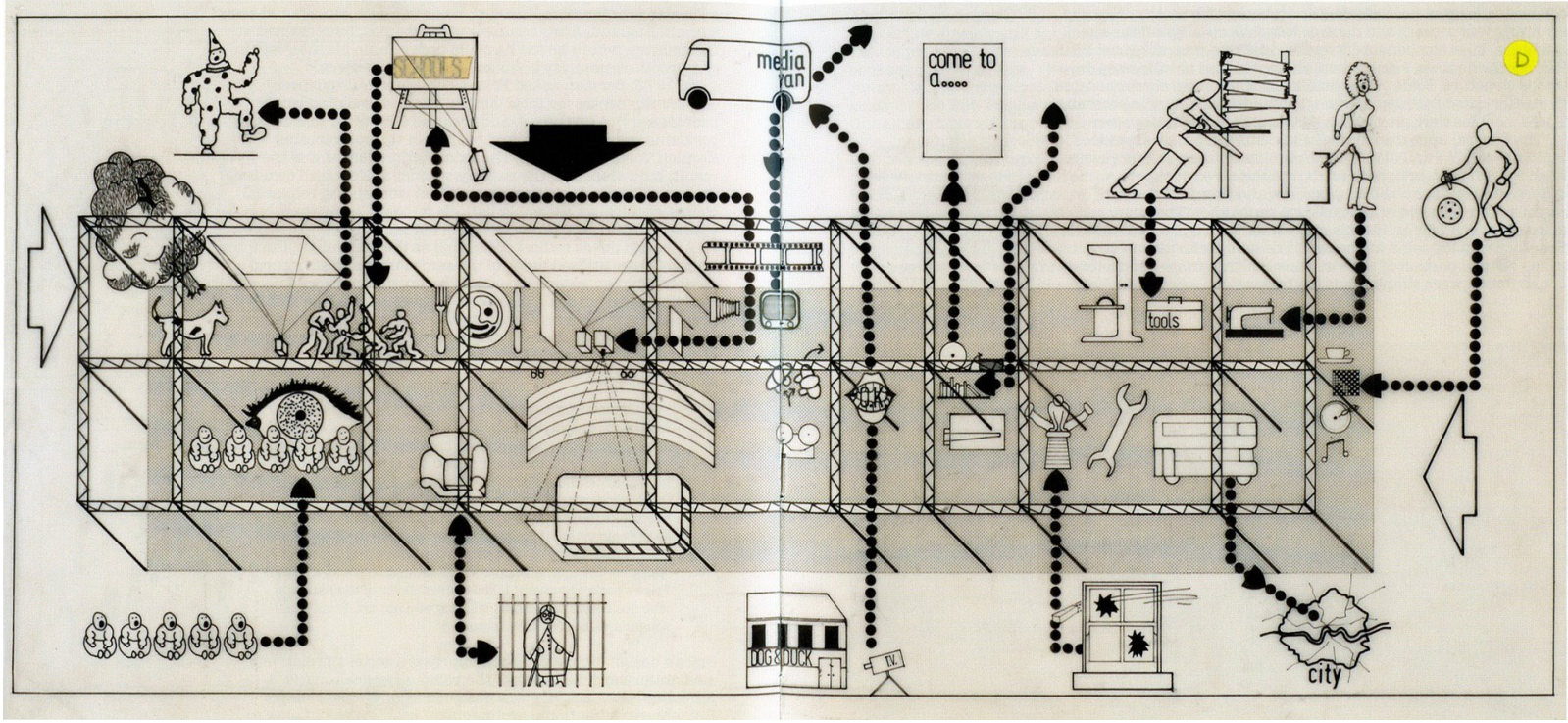

Plate 01. - Price, C. (1961). Fun Palace. 
Emerging in the late 1960 's is Gordon Pask. Pask, the thinker behind "Conversation Theory", postulated on the relevance of cybernetics in architecture. Pask understood that the built environment "perpetually interacts with its inhabitants, on the one hand serving them and on the other hand controlling their behaviour" (Pask, pp.70). This perspective was framed by the principle that architects are not merely the designers of buildings in isolation, but creators of "larger systems that include human components" (Pask, pp.70). Given the dynamic nature of human existence, architects therefore must produce dynamic architectural entities. Due to the humanistic and not merely functional role of architecture to a society, "the architect is responsible for building conventions and shaping the development of traditions" (Pask, pp.71).

John Frazer, a collaborator of both Pask and Price, would put forth his own ideas in the field with his notion of an "Evolutionary Architecture" of which the aim "is to achieve in the built environment the symbiotic behaviour and metabolic balance that are characteristic of the natural environment" (Frazer, 1995, pp.9). Frazer and other researchers at the Architectural Association in London embraced and benefitted from technological developments occurring in the field of computation and applied these emerging technologies in their projects.

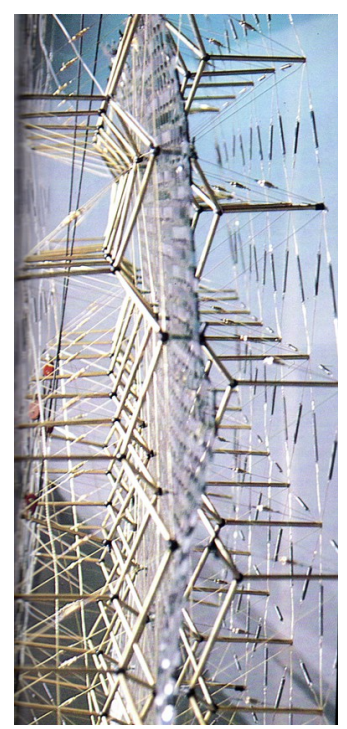

Plate 02. - Frazer, J. (1993). Interactive Skin.

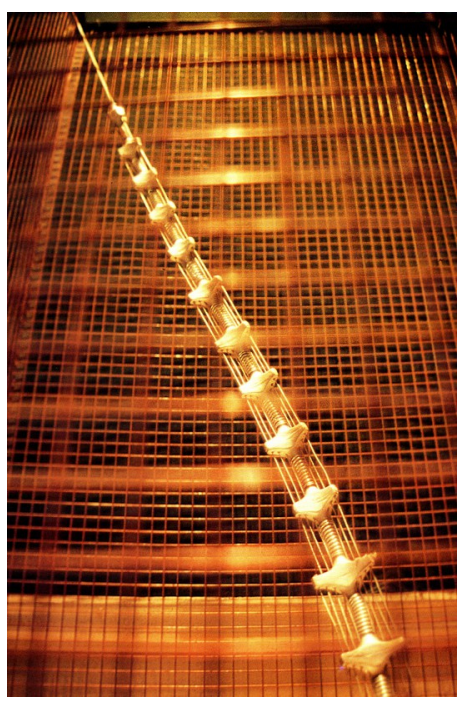

Plate 03. - Adekola, A. (1992). Interactive output device for displaying an emotional state. 
These early concepts suggesting development of expansive systems integrating humans with machines continued to develop through the 1990's and became influential on the field of Human Computer Interaction (HCI). As the general public began to reap the benefits of proliferated access to computational devices, MIT researchers Ishii and Ullmer observed significant "gaps between both cyberspace and the physical environment" (Ishii, 1997, pp. 1) and developed the notion of "Tangible Bits" which proposed "coupling the bits (the binary digits of computation) with everyday physical objects and architectural surfaces" (Ishii, 1997, pp.1). Ishii and Ullmer believed that there had been "too much bias towards graphical output at the expense of input from the real world" (Ishii, 1997, pp.3) and put forth the term Tangible User Interfaces (TUI) a new form of HCI in which physical objects and environments would be augmented by their coupling with digital information to transform "the world itself into an interface" (Ishii, 1997, pp.3).

Tangible User Interfaces build upon Mark Weiser's notion of "Ubiquitous Computing" (1991) where computational technology is so profoundly integrated into everyday life that it becomes "indistinguishable from it". Weiser speculates on a point in time when, like with earlier communications technologies, people have learned computing "sufficiently well, they cease to be aware of it" (pp. 94). Alongside his excited optimism he responsibly points out ethical issues surrounding privacy of personal information while pointing out the potential for individuals, businesses or governments to explore nefarious applications of technology. Weiser also brings to light the issue of communications protocols and stresses the need for a universally applied standard in order to achieve true ubiquity of computation.

Designer and creative technologist behind several recent interactive architectonic artworks Behnaz Farahi goes so far as to posit that Weiser's prediction that computation will cease to be noticable will manifest by the end of the $2^{\text {nd }}$ decade of the $21^{\text {st }}$ century (2013). I 
would refute Farahi's position and through Perpetual Shift, the artwork developed as a result of this investigation, aim to shed light on some of the ethical concerns admitted by Weiser as justification for why it may not be to human advantage for computational technologies to become invisible and absent from our awareness.

"Everyware", a post-millenium contemplation of how Weiser's predictions were playing out, was authored by Adam Greenfield. In describing Everyware as “information processing embedded in the objects and surfaces of everyday life" (2006, pp.18), Greenfield outlines many of the ways in which we are already living in an age of ubiquitous computing. However, his critical eye describes the situation as a "messy, hybrid, piecemeal experience" (2006, pp.215).

This realm of embedded computation has lead towards what Kevin Ashton termed an "Internet of Things" (Ashton, 2009); a world of "computers that knew everything there was to know about things". Ashton believes computers need to be empowered with "their own means of gathering information, so they can see, hear and smell the world for themselves". Whereas Ashton's position was rooted in supply chain management with goals of reducing waste and losses resultant from "the limitations of human-entered data"(2009), it is this ability to gather information which allows the built environment to achieve the adaptation and evolution imagined by earlier practitioners.

Ubiquitous computing and instances of context aware systems applied to the built environment since the beginning of the $21^{\text {st }}$ century have resulted in the realization architectural works and art installations which bear responsive, interactive or adaptive qualities, the characteristics of which will be subsequently discussed. Inherent to all three categories is the capacity to dynamically change in some manner. This perceivable change at the architectural scale is commonly achieved through illumination, display screens or physically kinetic material components. Even in a passive, static state the basic principles of architectural systems establish 
layered compositions of "facade, interior and structure, as a medium for expression. They affect the way passers-by perceive their surroundings and potentially engage them into dialogues with others sharing the space" (Tomitsch, 2008. p.2).

Architectural facades are powerful tools of communication because of their dominant scale in our built environment and thus ideal for the "transmission of signals or messages over distance for the purpose of control” (p.15) as suggested by James Carey's (1989) two views on communication. Buildings have the capacity to "increase the speed and effect of messages as they travel in space"(p.15) in their outward public expression and contribution to our collectively shared spaces. These qualities make buildings neat examples of the Shannon and Weaver (1949) transmission view of communication.

In reflecting on how the built environment can inform and influence human experience, there are numerous examples which could be considered. For instance, if architectural facades are implemented as platforms for advertising imagery and propaganda we can hypothesize that traversing through the city being subjected to persuasive messaging has the potential to inform our day to day decision making processes through exposure to the transmitted image, text and audible content. Additionally, the pervasive continuous presence of advertising in urban public space contributes to the normalization of the consumption of mass media and reinforces communication hierarchies of sender and receiver prioritizing the uni-directional rights of the facade owner to contribute to the creation of cultural meaning.

In addition to architectural materiality and proportion, or the capacity of kinetic components, we must consider static photography, illustrated image and text based graphics for their influence on the experience of the urban built environment. The exponential expansion of the advertising industry throughout the $20^{\text {th }}$ century bred the proliferation of signs and billboards of increasing scale and spatial density. Structures erected specifically for the purpose of 
displaying temporary advertising messages line urban rooftops and suburban highways. Flashing bulb patterns and sequentially animated neon signs celebrated the economic fever of high American capitalism achieving ultimate embodiment in spaces such as Times Square and the Las Vegas Strip. It is with urban signs and billboards that the rate of change in communicative content in the urban built environment began to accelerate at a pace at which the disconnect between architectural form and surface becomes noticeably apparent. Even more recently "urban screens have replaced neon lights, billboards and graphic signs as symbols and agents of high-tech urbanism and global capitalism on a massive scale" (Hoelzel, 2016. p. 372).

Innovative advancements in the application and programming of LED's implemented in urban screens function in high contrast to the static structures which contextualize them and imbue the built environment with a transformable, transient layer. Robert Venturi (1996) put forth architecture for the information age as a form of communication where a two-dimensional information layer coexists as a separate entity from the traditional physical frame of the architecture.

In addition to the fundamental expressive nature of traditional or contemporary static architecture, digital screen displays layered over or integrated into the surfaces of the built environment have contributed the possibility that filmic, animated, or scrolling imagery and text may be used to imbue the facade of a building with a dynamic communicative tool.

Though in the case of pre-programmed, curated content displayed over architectural surfaces, we do not necessarily achieve implementation of ubiquitous computing techniques as context aware systems, we do have the conditions of Mediatecture, "the integration of media and architecture" (Tomitsch, 2008. p.1); "installations in which displays are integrated into architectural structures" (Haeusler, 2009. p.13). Contemporary Mediatecture projects often expand the scale of the dynamic communicative surface to the size of an entire high-rise 
building, allowing its surface to morph and change appearances using light, the effects of which are often best experienced at night.

The overwhelming majority of examples of digital screens in the urban built environment are installed for advertising purposes whereby the content is curated by a media corporation selling screen time to clients or to promote the goods, services or brand of the organization who owns the screen. "Ambient displays, which are information systems that communicate information in the periphery of human attention" (Tomitsch, 2008. p.2) are examples of dynamically expressive elements of the built environment. When information and dynamic media are considered as a building materials from the commencement of a design process, "the elegant architectural integration of media architecture plays an important role in determining the perceived quality of its physical surroundings." (Vande Moere, 2012. p.4) and thus can contribute to a locations' perceived sense of place.

Given that advancements in technology permit a facade to be dynamically communicative at an architectural scale, we are faced with the question of what content could or should be transmitted through the facade as a medium. Here is where we can begin to ponder whether a facade, or broader environment, delivers content which is prescribed, preprogrammed, choreographed and/or edited (as in advertising/branding, news or governmental messaging) or if the facade interface is employed as a responsive, interactive or adaptive system.

Dynamic expression on the surface of a building can also be achieved by mechanical displays to produce physically kinetic facades. "A mechanical display consists of an actuator that constitutes mechanical movement, a surface that constitutes an architectural shape, and mechanical parts that change the direction of force" (Park, 2013. p.4). Many examples of kinetic facades employ repeated modular components which adjust their position in relation to some input data which drives them. A recurrent source of data in these examples is weather conditions 
at the building location, in particular the movement and intensity of the sun. Functionally, numerous precedents act primarily as solar shields or light modulating devices. In these cases, the resultant expressive surface could be interpreted to convey climactic environmental data or alternatively, to give us information about conditions within the building at that time.

A recent example of a responsive facade is the 2012 Al-Bahar Towers in Abu Dhabi by Aedas Architects (now AHR). Two 26 story high rise buildings are clad with a second skin, a kinetic facade whose components are driven by sun-tracking software that modulates the position of the facade panels to control the amount of sunlight which strikes the surface of the buildings' glass shell. The resultant effect is a significant reduction in energy costs, reduced glare and improved views out of the towers since the buildings' glazing does not require tinting or reflective treatment. The system is integrated into the structural frame of the building and includes numerous sensors which allow the building to respond not only to sunlight but also to sense the presence of strong winds in which case the kinetic panels will collapse to avoid being damaged.
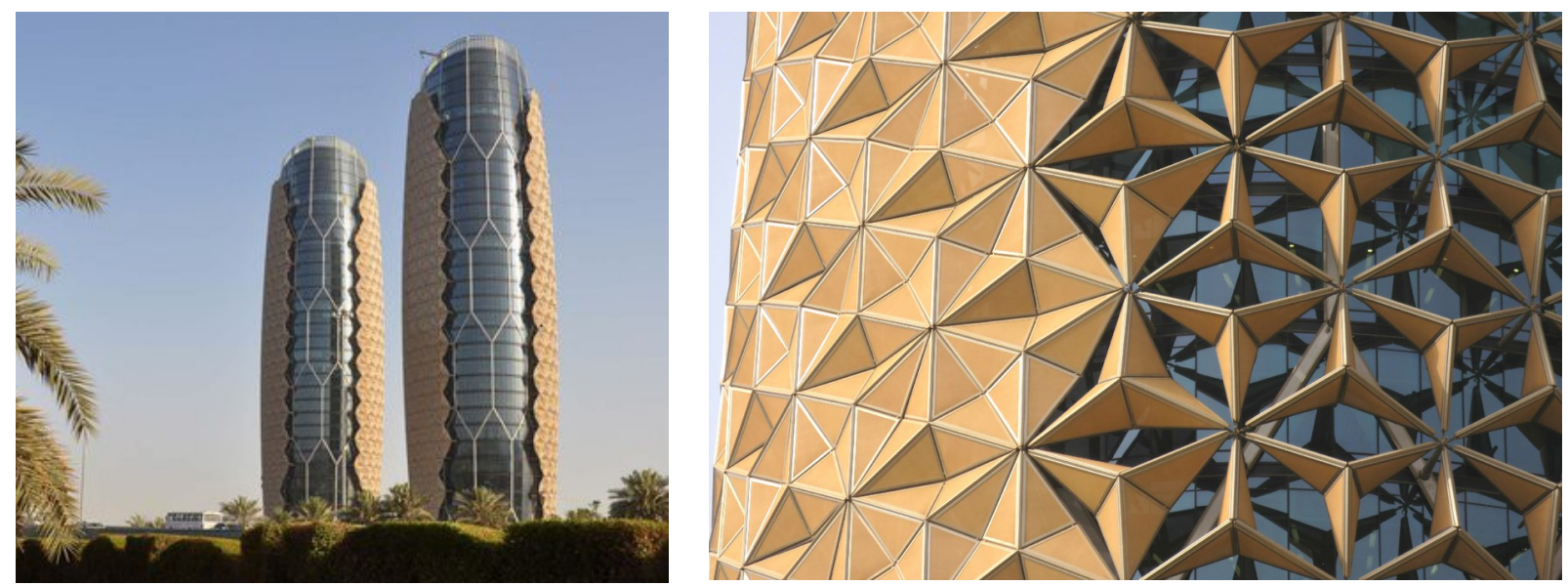

Plate 04. - AHR. (2012). Al-Bahar Towers, Abu Dhabi. Plate 05. - AHR.(2012). Al-Bahar Towers, Abu Dhabi. 
Kinetic facades whose movement and aesthetic transformation are programmed to alter configuration in relation to contemporaneously captured data are examples of responsive systems and expand the deployment of ubiquitous computing with a greater level of complexity. The same could be said for Mediatecture facades whose content is not traditional commercial advertising but whose illumination patterns are animated visual translations which relate to preestablished interpretation of sensor input data. This form of responsive system can be considered Pervasive Expressive Architecture, “defined as spatial representation of specific information relevant to the immediate environment or the people, who use that space" (Tomitsch, 2008. p.1) though it would not be considered a prerequisite that the input data be collected locally for a system to be categorized as responsive.

Furthermore, responsive mechanical displays are a form of "Embedded DataPhysicalization" (Willet, 2017. p.4), in that the composition of their physical materials is arranged to present data about themselves. The animated facade components would be considered "physical data referents - the real world entities and spaces to which data corresponds." A responsive facade driven by live sensor system data gives architecture a self referential mechanism; an environment may now produce the data which it's physical composition is simultaneously expressing. This eliminates all "spatial and temporal indirection" (Willet, 2017. p.7) making the communication real-time and site-specific.

An interactive system is a multi-loop system in which one enters into a conversation: a continual and constructive information exchange (Haque, 2006) between a person/people and an environment. As such, interactive systems in our built environment draw on some form of human presence or engagement as a source of data which drives and defines the dynamic transformation and expressive quality of the space.

In their seminal work on interactive architecture, Michael Fox and Miles Kemp state that 
“interactive space is built upon the convergence of embedded computation and a physical counterpart that satisfies adaptation within the contextual framework of human and environmental interaction" (2009, pp.12). Subsequently Bier and Knight put forth that "interactive architecture requires: automated kinetic systems with "embedded," "computational" control devices; "decentralized," "emergent," "bottom-up" control; "modular," "robotic" control systems; "biometric" recognition processes; and ultimately, "bio-robotic" control systems that adapt all sorts of actuators and sensors" (2010). In the artwork I have concieved of as part of this inquiry I have not ventured to implement any biometric capacity although the work does respond to the human bodily location in space thereby referencing relationships between computational technology and the physical biology of the body. By making possible the active engagement of people in the modification of their physical environment, interactive systems facilitate the notion of grassroots or bottom-up control and present us with an important contrast to facade-owner curated content.

There has been diverse exploration of interactive spatial systems at the scale of public art and sculptural installation; "experiences in which people actively construct public art within the boundaries created by the artist - where people both experience and contribute to the creation of the collective artwork." (Bryan-Kinns, 2014. p.124). The bottom-up, user driven interactive experience and expressive possibilities of digital interactive systems are faced with the limitations of physical hardware and operate within the biases of the framework scripted by the author of any cause and effect relationships manifested physically through the algorithms of the software code. Contexts where definiteively scripted input and output operations are not disclosed or apparent are described as existing in a "black box", defined by Weiner as a network in which "we do not necessarily have any information of the structure by which this operation is performed" (1948, Preface. pp. xi). Black box conditions are significantly restrictive to the 
bottom-up capacity of a network system and undermine the potential diversity of user-specific benefits offered by responsive, interactive and adaptive systems.

Increasingly emergent are examples of large scale Mediatecture facades which operate as interactive systems encouraging public engagement through some form of haptic, motion/proximity sensor-based or internet-connected interface, "such data driven synergistic environments bind architectural space and its' human counterpart in a behavioral dialogue, promoting real-time interaction." With the gradual intensification and sophistication of ubiquitous techology "enhanced spatial environments are now also increasingly being delegated the task of being more human. This implies acquiring a higher level of intelligence with attributes such as empathy, compassion, pro-activeness etc. becoming intrinsic qualities" (Biloria, 2016. p.102). The 'enhanced spatial environments' which Biloria is referencing are spaces which integrate ubiquitous computing networks and context-aware technologies.

This link with our built environment afforded to us by technology triggers a re-structuring of the context of human social interaction. Describing what he termed "the second basic feature of social life" (p.22) O’Neill (1985) put forth that "We seek out other bodies in society as mirrors of ourselves", "and this is because our own bodies are the permeable ground of all social behaviour" (p.22). As a built environment transforms over time, its anthropocentric quality emerges via it's ability to influence human social experience in a dynamic fashion. In the realm of interactive spaces, the potential in anthropocentricizing the built environment, that is "to project personality onto other entities as means of better relating to them" (Glynn, 2016, pp.1) is considerable. In conceiving a framework of interaction in a man-machine system, anthropocentric qualities of a built environment "help us to predict behaviours, to engage in them, as well as to maintain our interest" (Horowitz \& Bekoff, 2007. p.28). A space capable of expressing itself and it's understanding of the dynamic environmental conditions it shares with 
humans present within or without its physical boundaries begins to manifest a shifting "affective resonance", the basis for all human communication as described by theorist Sylvan Tomkins (1962). This would suggest that an environment may modify our affective response just as we may modify the response of the environment.

Evermore prominent, the broad based implementation of ubiquitous computing permits the evolution of adaptive systems which become interwoven with real-time "context-awareness, i.e. A display's ability to deliver "the right information at the right time". ... focuses on the technical recognition of human interaction patterns (e.g. presence detection, content suggestion, etc.), enabling the display to adapt its behavior to the specific characteristics of its social setting" (Vande Moere, 2012. p.2). Generating robust information shadows (Greenfield, 2006), objects, devices, furnishings, etc... making up the Internet of Things (IOT) manifest in unison such that built environments "acquire the characteristics of living entities, sending and receiving information, processing this information locally, and producing responsive global output. Such design informatics-based hybrid typologies can be seen as complex adaptive systems" (Biloria, 2016. p.108).

This system loop enabled by ubiquitous computing in which patterns of human behaviour are documented, computationally processed and used to generate the behaviours of an environment, produces conditions for an influential dialog between the two. In these conditions the built environment becomes a social actor "equipped with technologies that mimic typical behaviour of humans, animals or plants, such as physical features or emotions. Environments embodying social actor can invoke social responses from users". An environment with characteristics of a social actor is equipped to "evoke the feeling that they need our attention to survive, that we have to take care of them. Systems from this category rely on sensors and other pervasive computing technologies to communicate with people in a non-verbal direct or indirect 
way" (Tomitsch, 2008. p.3).

Tomitsch's connection between perception and non-verbal communication raises the question of how data, an essentially immaterial thing, can be translated into formats perceptible to people. In discussing designing for a broader spectrum of human senses, Maria Lehman notes that "architecture is biased towards the visual system" (2017, p.46) and underscores the amount of research done in this area. The established field of data-visualization "involves the mapping of data from numerical form into an iconic representational form in the attempt to provide humans with insight and understanding of a phenomenon" (Cox, 2004. p.71). Mediatecture facades and public display screens have the capacity to be employed for the visualization of data through a language expressed via colour, pattern of animation and image. In these cases, there is a direct relationship between data and visual composition; “"data-mapping” is the process of making a representation of numbers and correlated facts according to some convention of representation" (Cox, 2004. p.75). It is these conventions that form the basis of a perceptible language.

Parallels can be drawn between Kinetic facades which employ mechanical displays and the emergent field of Data-Physicalization, which is concerned with "physical artifact[s] whose geometry or material properties encode data" (Jansen, 2015. pp.2). In the context of responsive, interactive and adaptive systems integrated into architectural spaces "physical visualization inherently has the quality to directly inform people when decisions are made, to allow people to explore cause-and-effect relationships and to provide people with enjoyable, but contextually related experiences that could motivate and encourage" (Vande Moere, 2008. pp.6). Vande Moere's (seeking more prominent author of this position) proposition that we could be motivated and encouraged by a physical visualization suggests that our built environment can directly inform our behaviour. This exploration between cause-and-effect in the built environment is newly made possible by ubiquitous computing and in itself is a new behaviour which we may 
engage in. Vande Moere also suggests that persuasive computing "which focuses on using modern technology to change people's opinions or attitudes, or encourage long-term, persistent behavioral changes by providing real-time information within relevant spatial contexts" (2008. pp.6) is an application particularly suited to data-physicalization. It is important to note that Vande Moere stresses the importance of location; this highlights the fact that ubiquitous computing offers us finely grained site specific information and that though the internet connects us to communities at the scope of the entire planet it is remarkably powerful in its ability to connect users to the people and places where they themselves are immediately geographically situated.

Built environments which apply principles of data-visualization or data-physicalization bear the capacity to outwardly express information about their own condition, establishing realtime interactive communication loops with their occupants and establishing conditions where a data flow relating to the contemporaneous conditions of a space are woven into the phenomenological experience of said environment. The result is a built environment that is not only a reflection of the moment, but a contributor to the experience of the moment itself. In a discussion relating the content of Mediatecture and Kinetic facades to location, "the use of visual and physical representations of data that are deeply integrated with the data's physical referents" (Willet, 2017.p.1) are considered Embedded Data Representations; this suggests future trends in the built environment towards site specificity and contextual sensitivity.

A further extension of this site specific environmental communication comes forth in the form of in an adaptive system which can work to enhance the user experience as it "allows architecture to actively promote its very function" (Lehman, 2017. p.19). Lehman's writing discusses an adaptive sensory environment as one that by sensing "behaviour expressed by an occupant, it can respond by changing its configuration kinetically to bring added experiential 
value" (2017, p.23). Should an adaptive system be imbued with artificial intelligence this creates the possibility of a heightened degree of autonomy of the built environment and makes possible "new experiences that are more akin to conversing, performing, or negotiating with something that has its own awareness" (Brown, 2014. p.76). However, to be clear, artificial intelligence is not an area more broadly explored in this investigation nor specifically applied in the resulting artistic outcomes of my work.

Whereas data-physicalization intends to communicate data using proportional means based in numerical representation or authored visual languages which correlate information and its representation using a formulated system, Data-Sculpture is an alternate approach to the expression of data and employs metaphor to convey meaning. Metaphor "involves the cognitive process of understanding one domain of information in terms of another domain of information" (Lakoff \&Johnson, 1980). Through metaphor and thoughtful implementation of affordances, "the properties of an object that influences how it can be used", we can establish "a potentially powerful "visual" cue to convey meaning, as it foregoes higher-level visual abstraction and enables multi-sensory human sensations and subjective emotions" (Vande Moere, 2008. p.4). These methods are commonly applied in works considered Data-Sculptures which "embody the data in a perceivable presence, shape or form" and users "interpret these data-driven objects by the affordances the convey." (Vande Moere, 2008. p.4). Much like the field of data-visualization, data-sculptures employ "mapping in the presentation of visual metaphors... one system of attributes maps onto another to provide a new relationship of meaning” (Cox, 2004. p.77). Authors of these works "choose to intentionally make non-obvious connections between the signifier (the artifact) and what is signified (here, the data or the meaning of the dataset)" (Vande Moere, 2008. p.4).

With the progressive implementation of ubiquitous computing in the urban built 
environment, the result is the creation of a datascape "consisting of physical architecture blended with media infrastructure in variable ratios." (Stojsic, 2017. p.138). It is reasonable to conceive "we are moving from the city as an ensemble of static architecture/infrastructure to a screenmediated form of mobile relationality" (Hoelzel, 2016. p.375) and on towards Lev Manovich's notion of augmented space, "the physical space overlaid with dynamically changing information, multi-media in form and localized for each user" (Manovich, 2006. p.219).

\section{PERPETUAL SHIFT: INFORMATION INTERFACE}

Perpetual Shift, a responsive art installation, exists at the intersection of digital media, art and architecture, bearing a range of connections to the realm of ubiquitous computing and adding to evolving perspectives in the fields of installation art and interactive architecture by proposing a new mode of engaging with data through the physical built environment. The physical embodiment of the sculpture has the functional properties of a Tangible User Interface and employs an innovative approach to material application to generate multi-modal dynamic output (sight and sound). Though as a device Perpetual Shift is capable of being programmed to function as a form of data-physicalization, this artwork is a form of data-sculpture whereby location of the human body is interpreted as data which drives the actuation of the built environment. 


\section{PERPETUAL SHIFT: PHYSICAL DESCRIPTION}

Perpetual Shift is a responsive art installation designed to engage a human audience in a unique experience of space. This project is at once an artifact and an environment, a device and a spatial envelope. Incorporating electronic and computational components, the artworks' physical structure stands $8^{\prime}$ tall and occupies an area measuring $15^{\prime} \times 18^{\prime}$. The sculpture is conceived for installation in an open interior area of 2000 sq.ft.or larger. Elliptical in plan, the installation is comprised of two curvilinear surfaces arranged to suggest an enclosure while remaining open along one major axis.

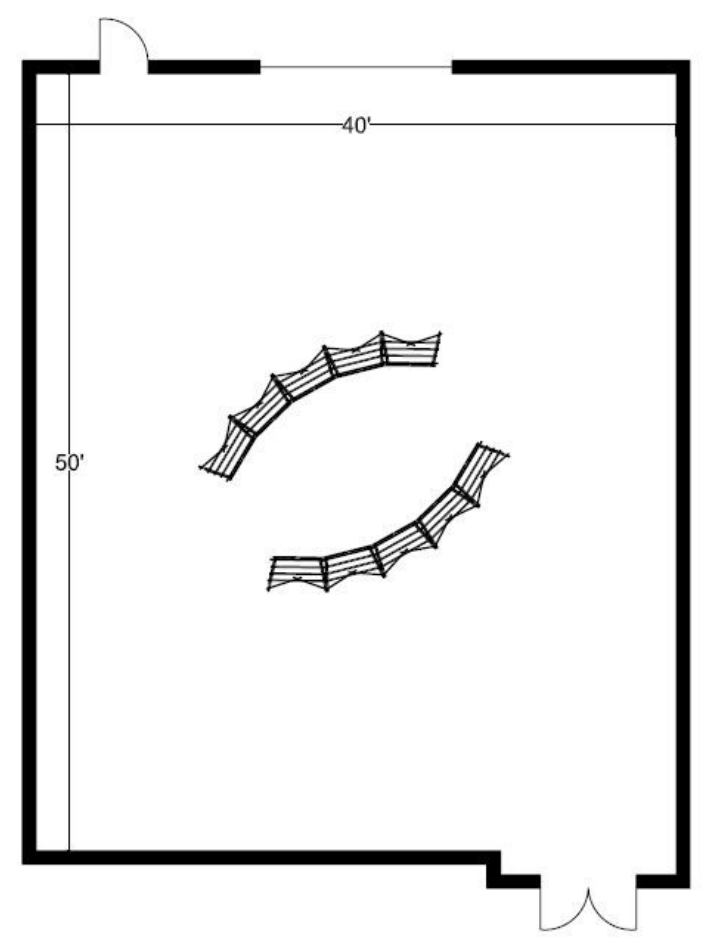

Ideallzed Plan of Installatlon Slte

Figure 01. - Aloisi, P. (2018) Perpetual Shift: Idealized Plan of Installation Venue

The structure is positioned in the center of the open area such that people may experience the built object from a range of distances as well as enter within the enclosure formed between the two upright surfaces. 


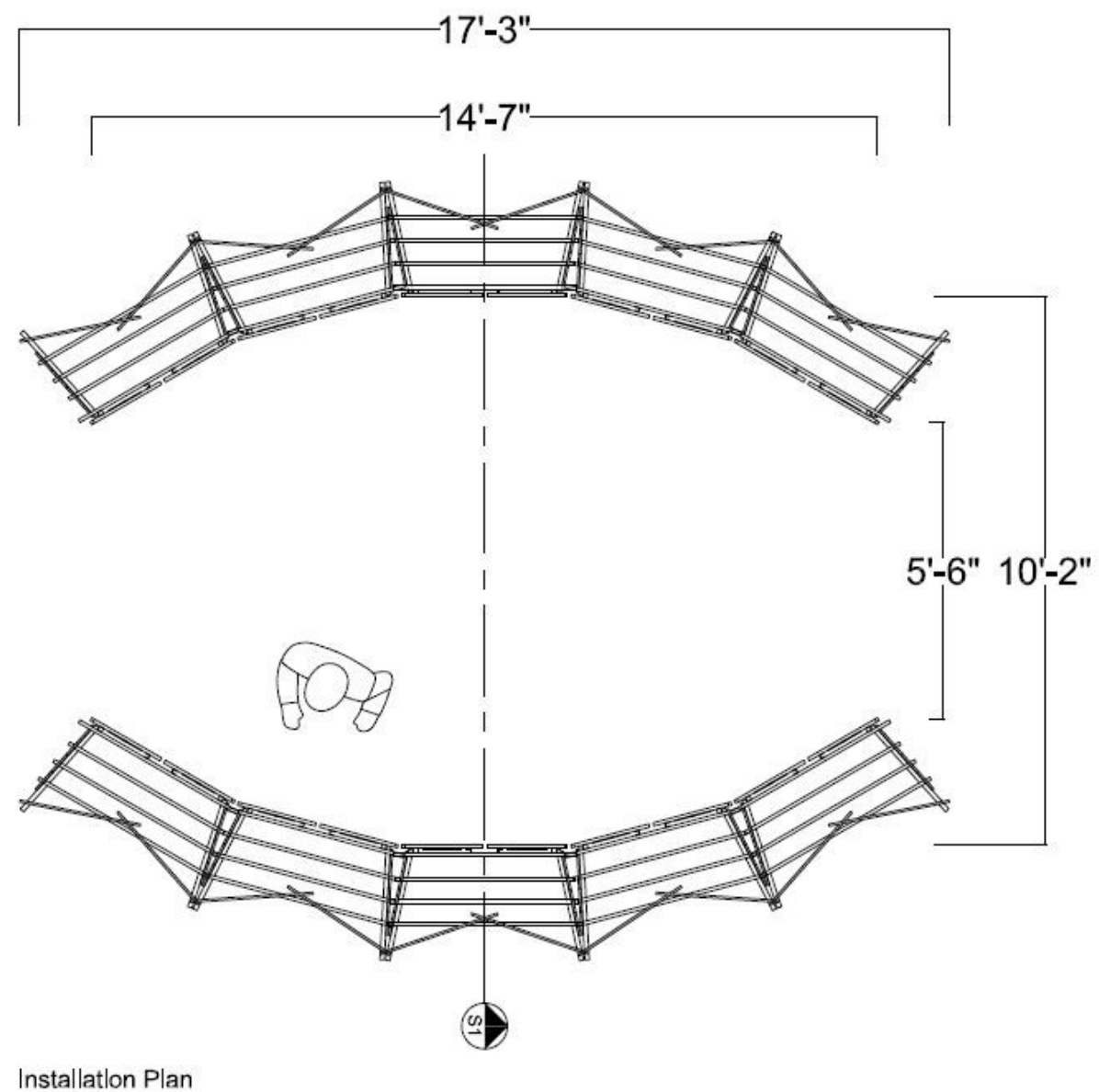

Figure 02. - Aloisi, P. (2018) Perpetual Shift: Installation Plan

A lightweight triangulated black wooden structure supports a regular grid of mirror-like, triangular stretched reflective mylar panels. The smooth shiny surface of the panels face inward onto the spatial enclosure while the exposed structural members are prominently visible from the outer perimeter creating the impression of being inside-out. The 'rear', or 'outer' side of the triangular panels are also reflective in nature but visually obscured by structural components and electronics infrastructure. 


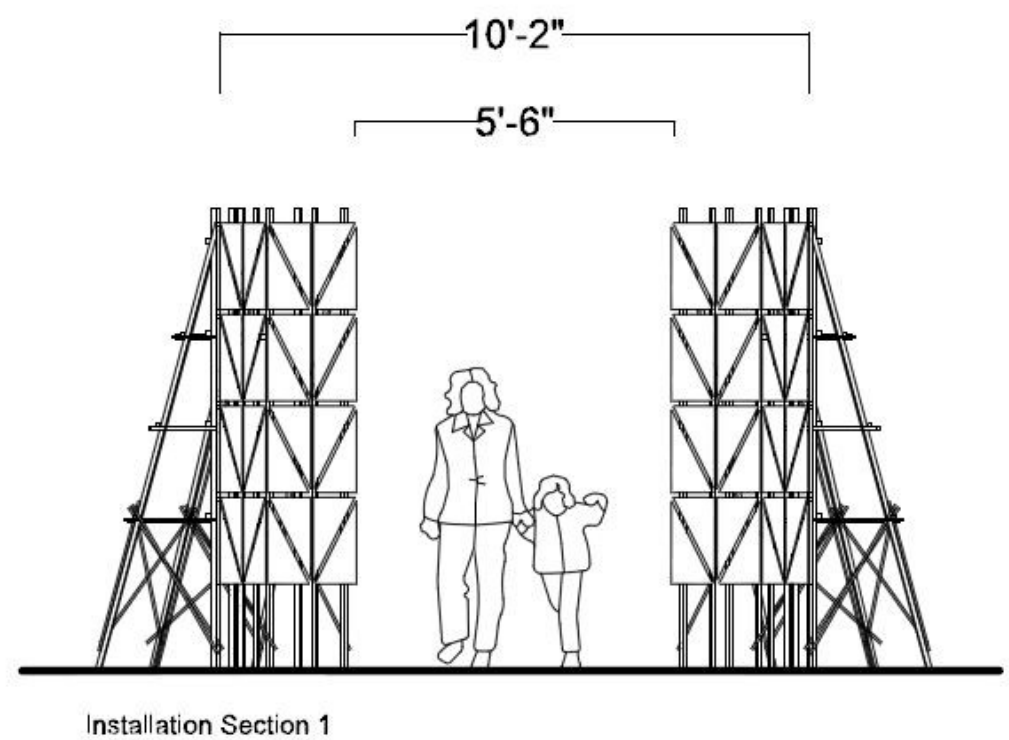

Figure 03. - Aloisi, P. (2018) Perpetual Shift: Installation Section 1

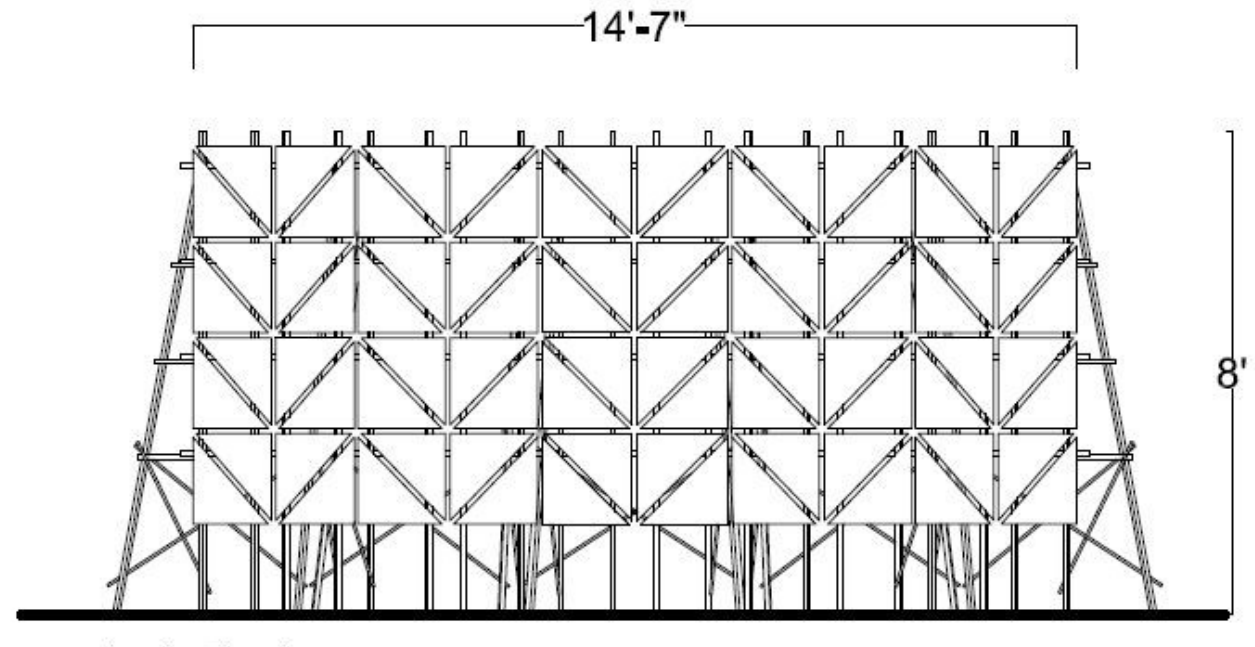

Interior Elevation

Figure 04. - Aloisi, P. (2018) Perpetual Shift: Interior Elevation

All components of the artwork are modular and affixed together using plastic cable ties permitting components to be quickly swapped out if damaged; the modular design also permits to work to be easily scalable. Integrated into the rigid structural assembly are electrical cables which deliver power to cell phone vibration motors affixed to the rear of each reflective panel. Additionally, a distance sensor (Lidar) and RGB LED lighting module are mounted to each 
quadrant of the structural wooden frame. A micro-controller and other circuitry components are discreetly housed within the base of the sculpture. The interface operates using $5 \mathrm{~V}$ DC current and therefore requires a connection to a source of electricity.

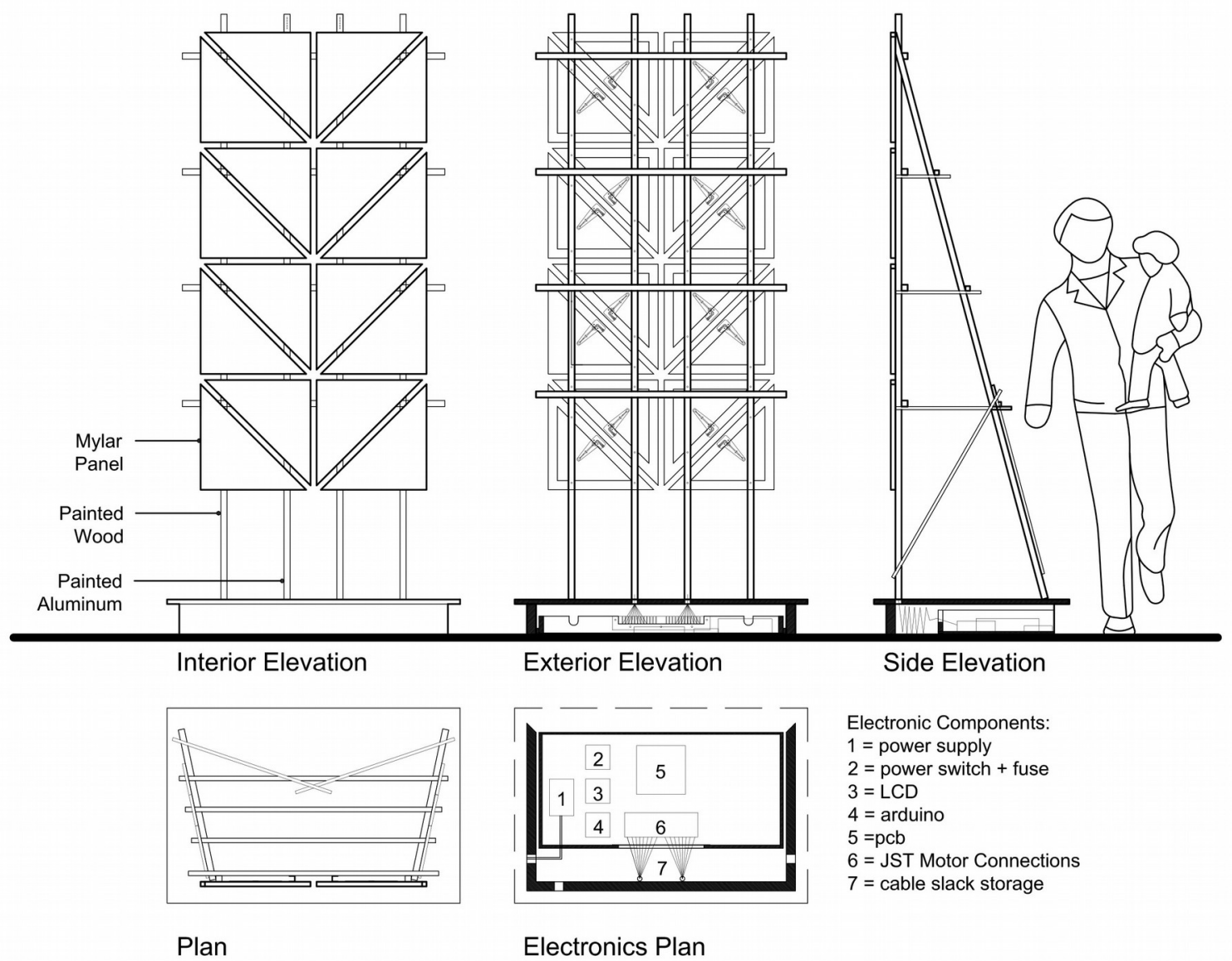

Figure 05. - Aloisi, P. (2018) Perpetual Shift: Modular Segment Details

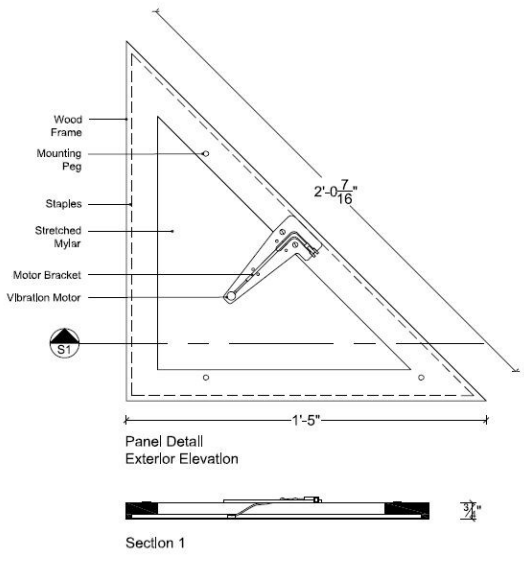

Figure 06. - Aloisi, P. (2018) Perpetual Shift: Panel Detail

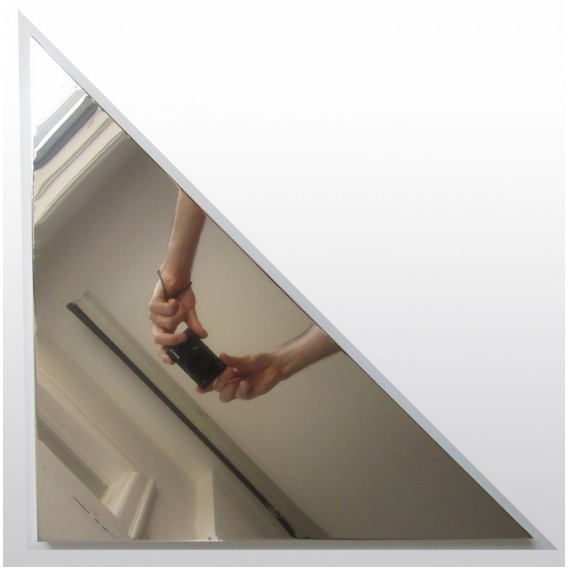

Plate 06. - Aloisi, P. (2018) Perpetual Shift: Panel Reflection 


\section{PERPETUAL SHIFT: EXPERIENTIAL DESCRIPTION}

The shifting kinetic quality of the installation connects the human experience of space to time through the impermanence of its embodiment and embeds the artwork in an ephemeral state of continual transformation, perpetually shifting. A primary experiential effect of the installation is the visual fragmentation of the reflected image appearing across its surface. The convex triangulated arrangement of the mirror panels simultaneously reflect multiple perspectives of the environment which the sculpture occupies including the people within it; thereby intrinsically offering a form of contemporaneous contextual visual information. Whereas numerous related precedents have solely employed animated light to visualize data, Perpetual Shift will physicalize data by giving inorganic material a kinetic action linked to input readings sourced from integrated sensors to cause mechanical agitation of the stretched mylar, resulting in subtle visible movement of the material as well as an animated distortion of the image in its reflective surface. Additional sensory stimulation is generated by the ability of the stretched mylar to amplify the sound of the normally quietly operating cell phone vibration motors (the pitch of the sound varies with speed of vibration). The animated characteristics of the visible and audible vibrations will be approached as manifestations of the built environments' various emotive states as expressed by a numbered series of animation states outlined in Table 1 - Framework of Interaction and accompanied by Figure 3 - Framework of Interaction Schematic. 
FRAMEWORK OF INTERACTION

\begin{tabular}{|c|c|c|c|c|c|c|}
\hline $\begin{array}{l}\text { SENSOR } \\
\text { INPUT } 1\end{array}$ & OUTPUT 1 & & & OUTPUT 2 & $\begin{array}{c}\text { BUILT } \\
\text { ENVIRONME } \\
\text { NT }\end{array}$ & STATE \\
\hline \multirow[t]{2}{*}{$\begin{array}{l}\text { Human } \\
\text { Proximity }\end{array}$} & $\begin{array}{l}\text { Vibration Motor } \\
\text { Effect A }\end{array}$ & $\begin{array}{l}\text { Vibration Motor } \\
\text { Effect B }\end{array}$ & $\begin{array}{l}\text { Vibration Motor } \\
\text { Effect C }\end{array}$ & $\begin{array}{l}\text { LED } \\
\text { Effect A }\end{array}$ & $\begin{array}{l}\text { Empathetic } \\
\text { Characteristic }\end{array}$ & \# \\
\hline & $\begin{array}{l}\text { Sound } \\
\text { Pitch / Volume }\end{array}$ & $\begin{array}{l}\text { Reflected Light } \\
\text { Movement }\end{array}$ & $\begin{array}{l}\text { Reflected Image } \\
\text { Clarity/Distortion }\end{array}$ & \begin{tabular}{|l} 
Light \\
Brightness, Colour \\
Animation
\end{tabular} & & \\
\hline None & Slow - Pulsating & Animated-slow & Distorted - significant & Blue / Aqua - Pulsating & Lonely, Needy & 0 \\
\hline Distant & Fastest & Animated - fastest & Distorted - most & White-255-flash & Luring & 1 \\
\hline Near & Medium & Animated - little & Distorted - little & $\begin{array}{l}\text { Orange/Golden }- \text { Bright } \\
\text { Pulsate }\end{array}$ & Acknowledge & 2 \\
\hline Beside & Slow & Animated - somewhat & Distorted - somewhat & Warm White - Glowing & Calmed & 3 \\
\hline Inside & Off & Static & No Distortion - Clear & Pinkish - Glowing & Static & 4 \\
\hline $\begin{array}{l}\text { Multiple } \\
\text { People } \\
\text { Inside }\end{array}$ & Animation Sequence & Animation Sequence & Animation Sequence & Animation Sequence - 200 & Excited, Playful & 5 \\
\hline
\end{tabular}

Table 01. Aloisi, P. (2018) Perpetual Shift: Framework of Interaction

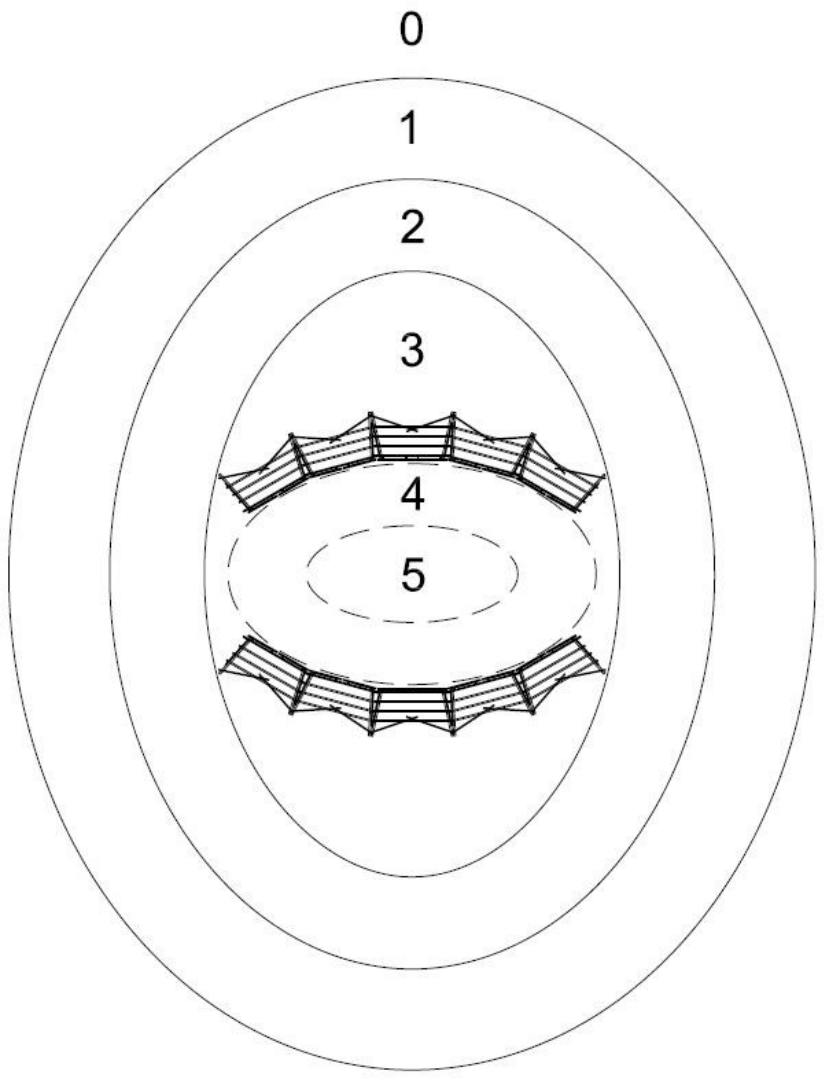

Framework of Interaction Schematic

Figure 07. - Aloisi, P. (2018) Perpetual Shift: Framework of Interaction Schematic 
Systemically, as a conceptual artwork, Perpetual Shift is conceived of to operate as a reactive environment imbued with persuasive intentions. In further contrast to related precedents, the framework of interaction operating in Perpetual Shift is inverted, meaning that engagement with the artwork's sensors results in de-activation or quieting of the system. Driven by cell phone vibration motors, the environment defaults (State "0" - when no bodies are present within range of the systems sensors) to an animated state of vibration intended to attract attention to itself by agitating and blurring the reflection of the world around it. This vibration also causes the work to emit a fluctuating audible hum which emanates from the drum-like membranes of stretched mylar. Overall, the sculpture's mirrored surfaces form an enclosed gathering space. The internal space within is illuminated by LED light of modulating tone and brightness resulting in the projection of an animated shadow outwardly into the space the structure occupies, thus amplifying the influence of the structure on human perception of the environment. Additionally, ambient light in the environment will be animated and distorted as it reflects off the surface of the vibrating skin. The animation of the default state is designed to attract the attention of people present in the environs and to entice their curiosity to enter into the man-machine system and engage with it.

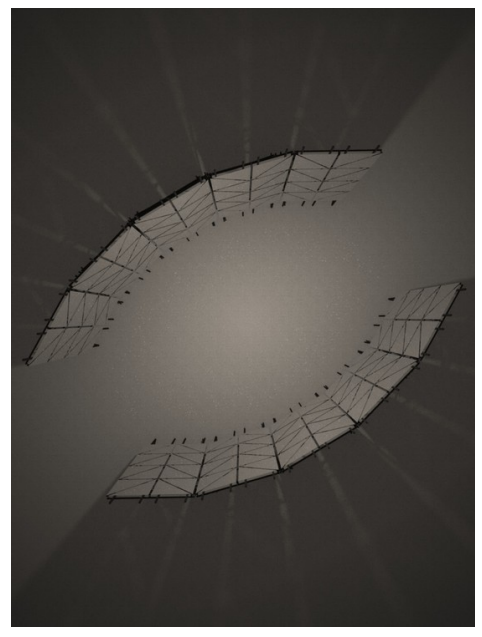

Plate 07. - Aloisi, P. (2018) Perpetual Shift: Installation Bird's Eye Perspective Rendering 
Upon physically moving towards the artworks' structure and coming within range defined by one of several distance sensors distributed around the perimeter of the structure, Perpetual Shift is triggered and startled into alertness. Bright white light flickers and pulsates from within to alert human peripheral vision. The vibration of the reflective panels is amplified to its maximum and a rapid sequence of ramping and descending animated auditory and visual distortion is transmitted. Needy, calling out to the public, Perpetual Shift aims to attract people towards itself by making us aware of an exchange between body and built environment. The built environment wants attention, demands ones' presence; acts out in an aggravated manner to captivate our gaze and draw people in.
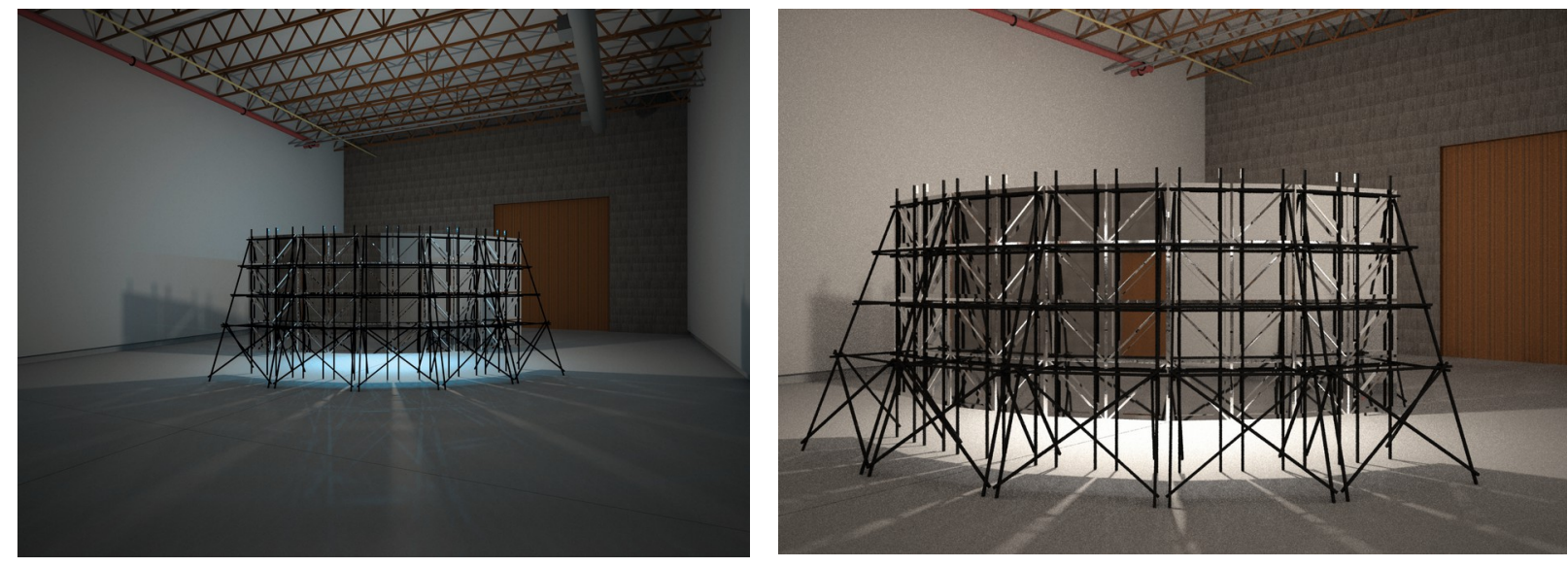

Plate 08. - Aloisi, P. (2018) Perpetual Shift: Zone 0

Plate 09. - Aloisi, P. (2018) Perpetual Shift: Zone 1
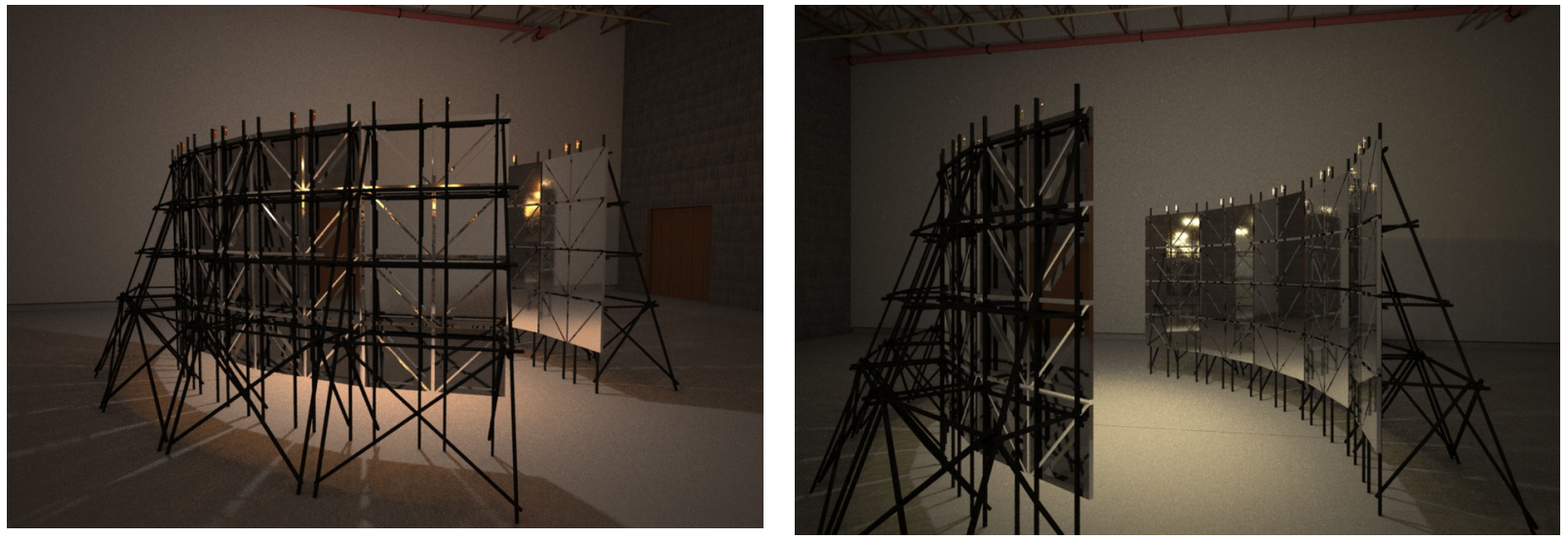

Plate 10. - Aloisi, P. (2018) Perpetual Shift: Zone 2

Plate 11. - Aloisi, P. (2018) Perpetual Shift: Zone 3 
As one is drawn into engagement with the built environment the actuation of the kinetic aspect of the work becomes apparent and the person can observe the distorted reflection of themselves and other elements of the given spatial context of the installation. As sensors return shorter and shorter distances between the human body and the structure to the systems' microprocessor, Perpetual Shift begins to calm its behaviour, stabilizing lighting conditions, dimming and fading through an animated colourscape. At intermittent positions, as the sensors interpret the increasing proximity of a person, the system outputs patterns of haptic vibration which ramp up and down similarly to the rate of change of the lighting within the enclosure. Though the frequency of vibration of the reflective film slows almost to a standstill, the visual image in the reflection remains distorted denying the experience of a true reflection of self. Through this behaviour the space continues to engage and lure the human subject into its immediate proximity.

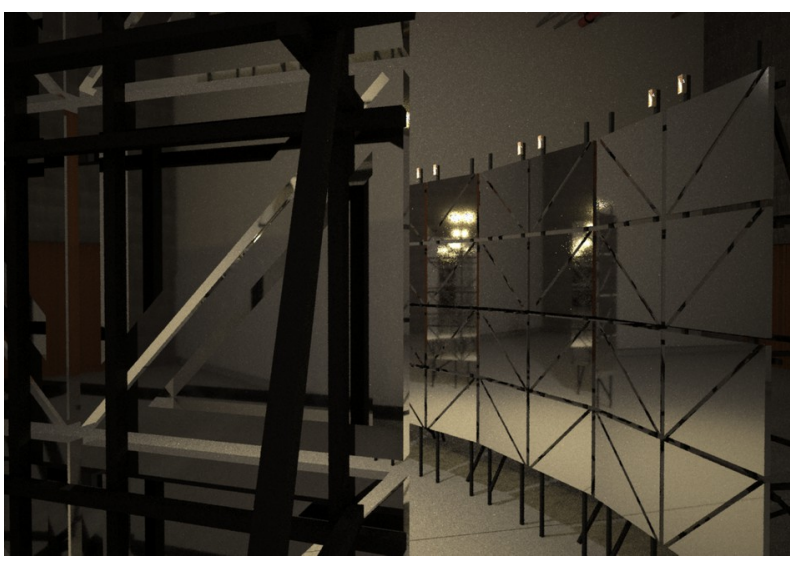

Plate 12. - Aloisi, P. (2018) Perpetual Shift: Zone 3

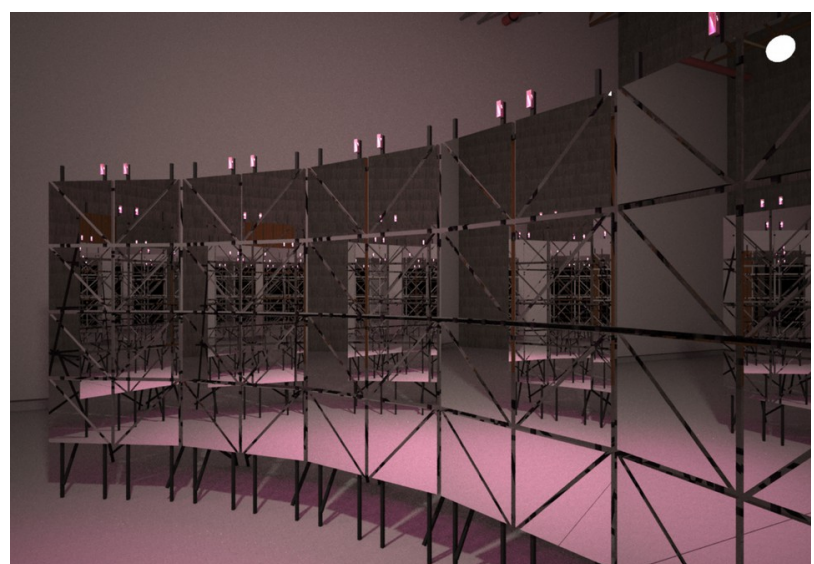

Plate 13. - Aloisi, P. (2018) Perpetual Shift: Zone 4

Upon entry through the threshold into the enclosure of Perpetual Shift the environment achieves its desired state of human occupancy and is pacified into a tranquil state. The vibration motors become silent and cease to agitate the image reflected in the mylar panels thus the person is offered a clear, static view of themselves projected into a fragmented space of multiplying 
reflections. Lighting within the inner space slowly pulsates towards warmer, blushing pinkish hues. The space and its occupant maintain this state of equilibrium for as long as these conditions are satisfied. However, if the person exits the threshold, Perpetual Shift exhibits no patience, returning to its agitated state when the person vacates the enclosure. The experiential qualities of the environment embody persuasive technology and are addictive by design; an artifact of the attention economy.

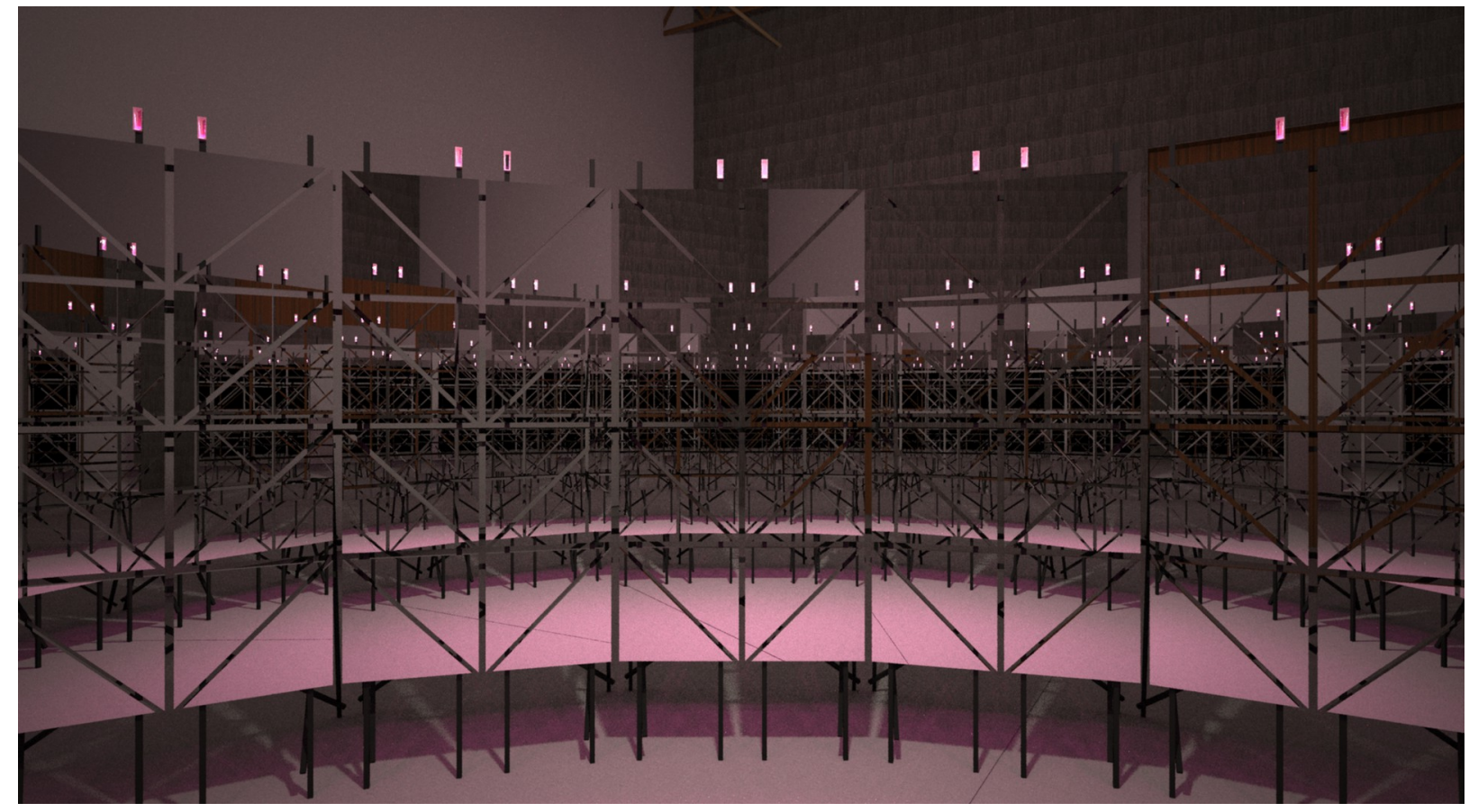

Plate 14. - Aloisi, P. (2018) Perpetual Shift: Zone 5

However, once the environment has captivated human attention, is occupied and calmed to its relaxed state, Perpetual Shift is prepared to offer positive reward for human congregation in order to encourage social interaction in real life. If the system senses multiple people within the enclosure together it provides conditions stimulating to their shared real life interaction in the form of a choreographed performative sequence of vibration, sound and light. 


\section{PERPETUAL SHIFT: EXTENDED COMMUNICATIVE QUALITIES}

Perpetual Shift is communicative in various capacities. Sensorially, via an embodied interaction in a built environment as described above, and psychologically/intellectually through metaphor and underlying cultural constraints and conventions arising from it's physical characteristics. Aesthetically, the artwork presents itself with a clear sense of structural organization and precision in its symmetrical geometric arrangement. As one approaches the artwork it's clean, but raw, exposed structure is emphasized and oriented outwardly towards the human body. The triangulated utilitarian framework makes visual reference to that of an advertising billboard as do the overall proportions of the work in that a simple framework is configured to support a thin communicative plane, in this case made up of reflective mylar panels. By reducing the surface plane to a $1 \mathrm{~mm}$ thick film Perpetual Shift emphasizes the moment of physical separation between public and private implied by an architectural facade.

Whereas from a distance the expressed structural integrity of the framework suggests stability and permanence, upon closer inspection its' method of assembly, using plastic cable ties, implies fragility and impermanence, thus opening up the possible interpretation that the construction may be temporary in nature. This temporal joinery method, modularity and repetition of standardized structural components contribute to a sense that the installation could be assembled and disassembled quickly, is portable/transportable, reconfigurable and scalable, thus imbuing the work with ties to mass-production. By exposing wiring and the workings of the electrical/computational system Perpetual Shift presents the built environment as a machine-like entity and reveals the tactile nature of the inner workings of perceptibly sleek devices. These qualities may also suggest a form of provisional architecture in particular when layered with the material connotations of reflective mylar, commonly employed in disaster relief efforts.

In this work, double sided reflective mylar, a synthetic polyester resin, is stretched taught 
over rigid frames in a process akin to stretching an artists' canvas. This results in a smooth, glossy, mirrored surface within which it is possible to see one's reflection clearly.

The self inspection afforded by this mirrored surface draws on narcissistic tendencies afforded by the inward scope of social media where self curation of self image drive selfie culture.

Though obscured by the black line work of the structural frame, the ability to see a reflected image of the sculpture's contextual environs in the mylar film adds a virtual layer to the surface of the physical construction. The fragmented reflected image dynamically changes as one moves through space and as such, the visibly perceived surface of the artwork is in continual life-like flux. This alludes to our continuous engagement with technology in the era of ubiquitous computing and technology's intervention into our perception of the world; the reflective material distorts the reflection of the world around us serving as a metaphor for technology's effect on our lives. The mirrored material also has connotations to surveillance and thereby issues of privacy. In Perpetual Shift the built environment monitors human behaviour as in the automated operational systems of a building given a detailed awareness of human presence. In this work space is letting us know that it knows that we're present.

The expansive dissemination of personal communication devices has literally transformed humans are beacons of communication. In this work there is a somewhat ironic use of cellphone vibration motors, typically employed to make communications more discreet, here they are used to produce and amplify sound. Contemporary cell phone bearing humans exist in a learned relationship to the haptic effects of cell phone vibration motors. Associated to App notifications sequences of vibration are uniquely designed to garner our attention and trigger our reaction, informing us that there is some piece of information awaiting retrieval. The bulk of haptic notifications are triggered by social media apps which lead the attention economy by offering users dopamine stimulation so that a craving for this gratification is developed over 
time. Many cell phone users also describe feeling vibrations even when they do not occur due to the anticipation built up by a system programmed to be addictive by design.

Much like the common mirror glass materiality of commercial high-rise buildings, from within the center of the suggested enclosure one is confronted with the glaring opacity of a mirrored surface. From this vantage point in space Perpetual Shift produces a synthetic virtual depth via echoing reflections in the opposing parallel mylar surfaces. The result is an atmosphere which is encompassing immersive and infinite.

\section{PERPETUAL SHIFT: FUTURE DEVELOPMENT}

Outside of the context of the Master of Digital Media thesis I envision continued development of the concepts and interface developed in Perpetual Shift. I aim to pursue various funding opportunities and/or sponsorship so as to deploy a work at the scale of that described in this document. I am also interested in exploring further development of an adaptable framework capable of deployment in various configurations in response to spatial conditions of diverse installation sites. An iteration of this work has been shortlisted for production and installation as part of Sheridan College's Temporary Contemporary project for 2018/19. Whereas I have chosen to apply the physical interface of the structure in a responsive artwork bearing the characteristics of data-sculpture, there is equal potential to employ the interface for the purpose of dataphysicalization. Given the opportunity to continue to develop this work through an iterative design process I see potential for the exploration of a more robust, element resistant version of the interface employable outdoors in an exposed public environment. 


\section{CONCLUSION}

The primary inspiration for Perpetuaal Shift is Mark Weiser's notion of Ubiquitous Computing. As a critical work of installation art which references architectureal facades Perpetual Shift reflects on some of the implications which widespread and increasingly sophisticated application of Weiser's concept fosters. Additionally, as an extension of the fields of data-visualization and data-physicalization, this work pushes into the realm of data-sculpture by manifesting an artists' translation of human presence into atmospheric transformation of the built environment as part of an encoded input/output, sensor/actuator relationship. This transformation of the built environment results in modulated perception of material, form and space thus altering the cumulative experience thereof. The artist-designed characteristics of this experience are developed as to influence human movement and behaviour in space by imbuing built form with an expressive capacity to hightlight the potential of the built environment, specifically architectonic surfaces, to act as a communicative interface coercive of our actions for its own (or owners), mutual, or human benefit. 
APPENDICES:

APPENDIX 01.

DOCUMENTATION OF ITERATIVE DESIGN PROCESS AND PROTOTYPING 

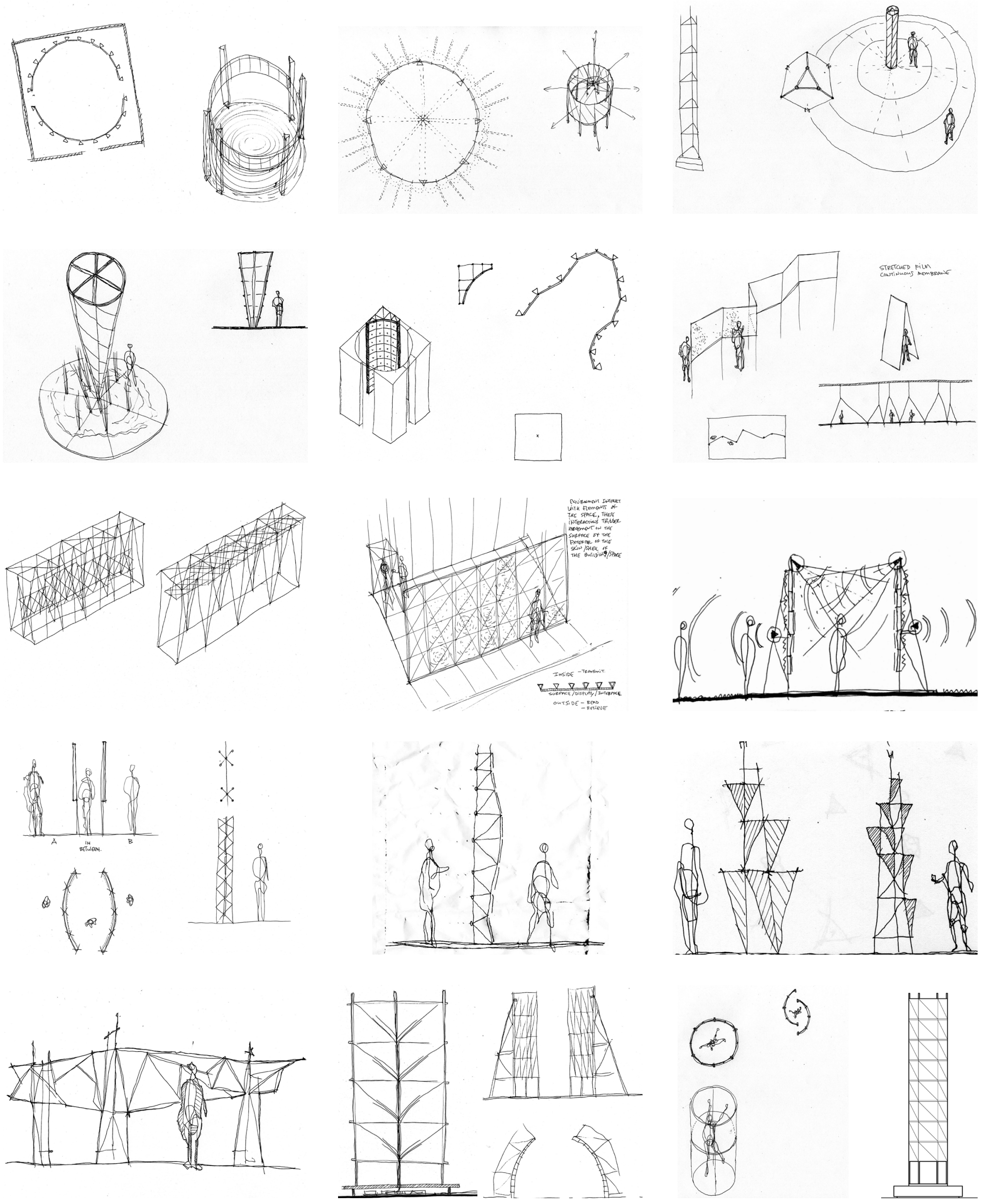


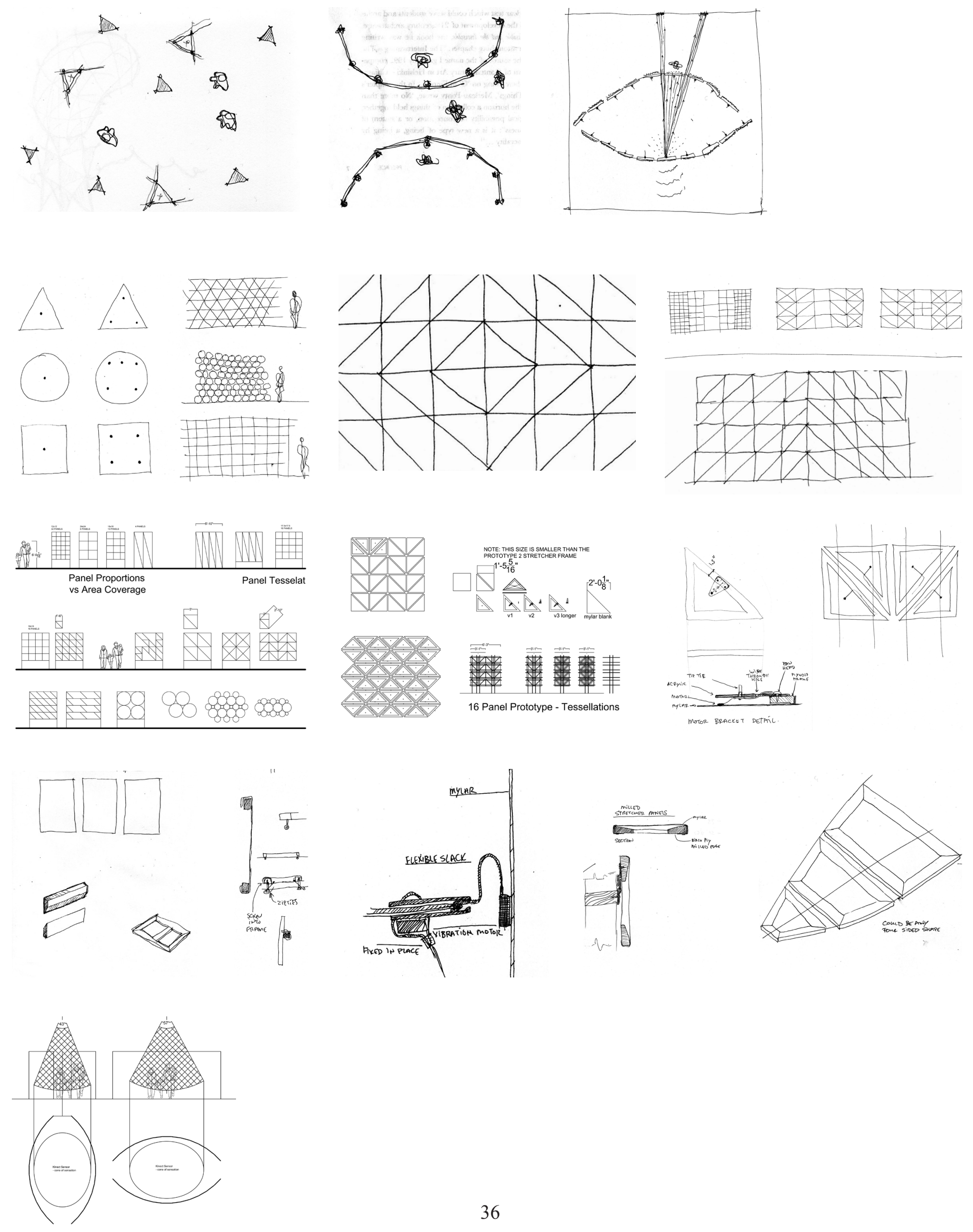



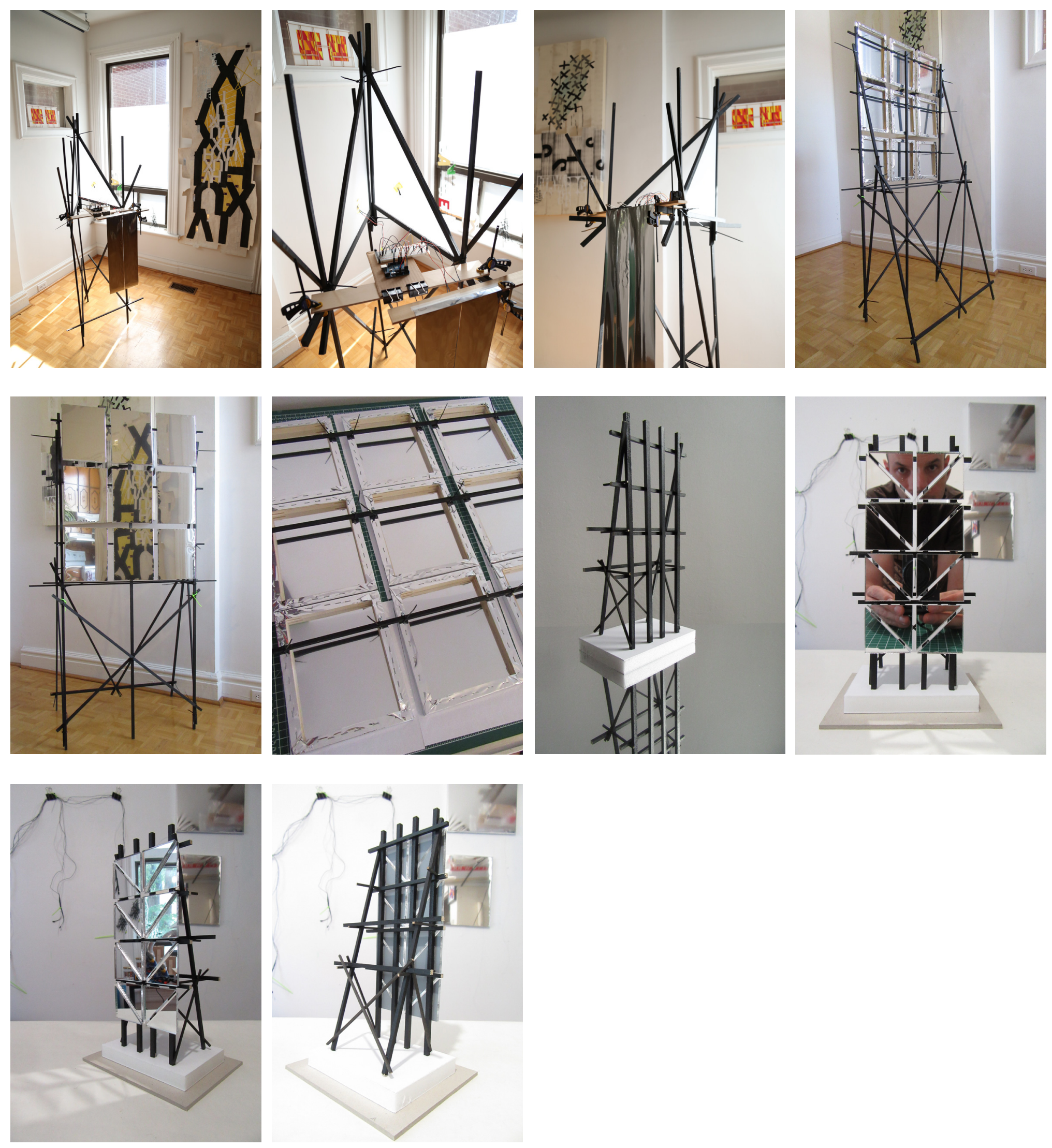

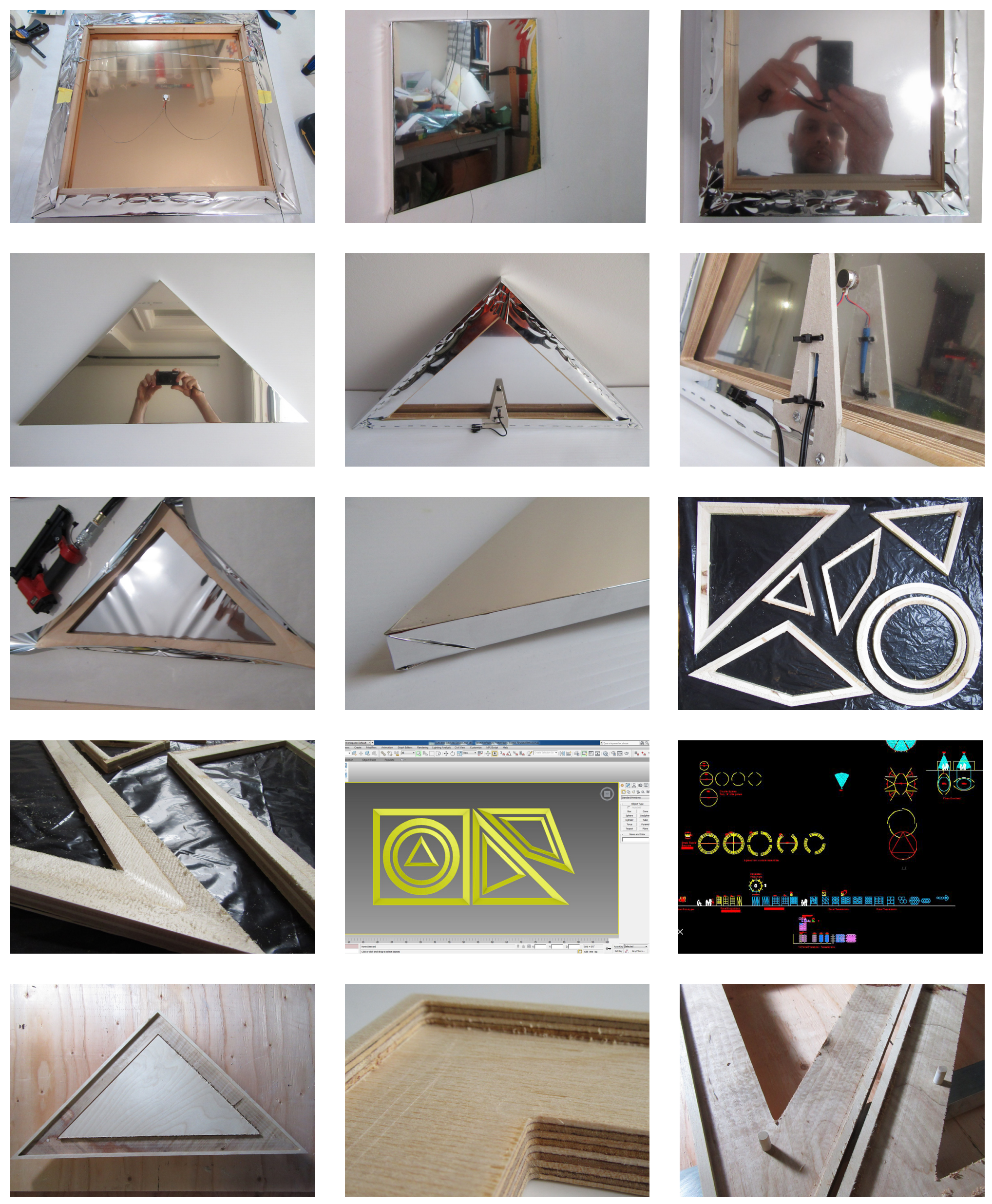

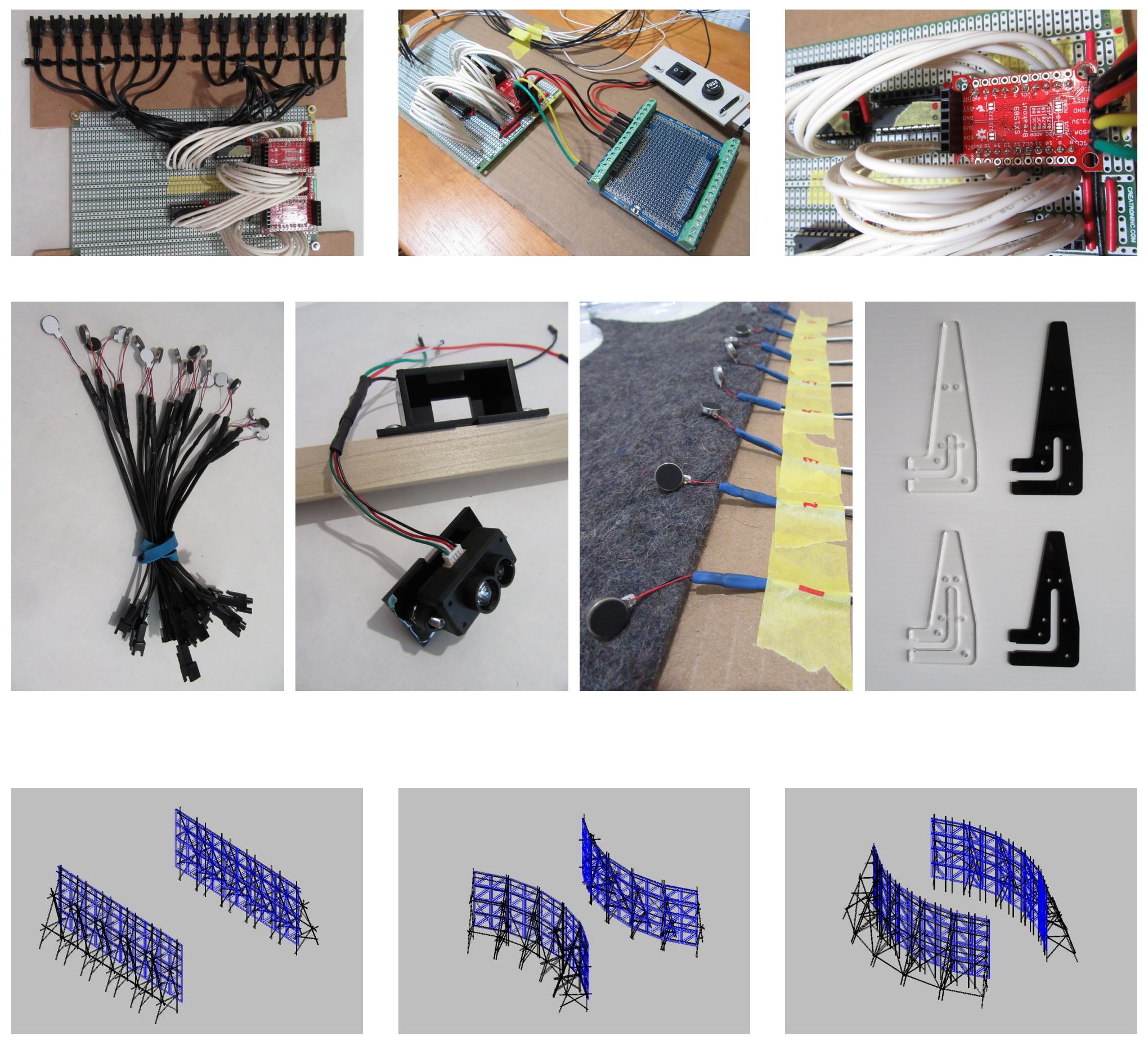


\section{REFERENCES:}

Ashton, K. (2009, June, 22). That 'Internet of Things' Thing. Retrieved from www.rfidjournal.com/articles/view?4986

Biloria, N. (2016) Design Driven Research Experiments in Interactive Architecture. In Beesley, P. and Roushan, A. Living Architecture Systems Symposium White Papers (pp.99-108). Waterloo, Ontario: Riverside Architectural Press.

Brown, O., Gemeinboeck, P., Saunders, R. (2014). The Machine as Autonomous Performer. In Candy, L \& Ferguson S. Interactive Experience in the Digital Age: Evaluating New Art Practice. (pp.123-138). London, Springer.

Bryan-Kinns, N. (2014). Mutual Engagement in Digitally Mediated Public Art. In Candy, L \& Ferguson S. Interactive Experience in the Digital Age: Evaluating New Art Practice. (pp123-138). London: Springer.

Carey, J. (1989). "A Cultural Approach to Communication." Communication as Culture: Essays on Media and Society. Boston: Unwin Hyman.

Candy, L. \& Ferguson S. (2014). Interactive Experience, Art and Evaluation. In Candy, L \& Ferguson S. Interactive Experience in the Digital Age: Evaluating New Art Practice. (pp.1-10). London, Springer.

Cohen, A., Hoskins D., Ito T. And Miller I. (2017). Experience Index. Baltimore, MD: Gensler Research Institute. URL: https://www.gensler.com/uploads/document/552/file/GenslerExperience-Index-2017.pdf

Cox, D. (2004). The Art and Science of Visualization: Metaphorical Maps and Cultural Models. Technoetic Arts: A Journal of Speculative Research Volume 2 Number 2 (pp.71-79. doi: 10.1386/tear.2.2.71/0. Chicago, IL: University of Illinois.

Clinch, A. \& Alexander, J. (2016). Survey Of Pervasive Displays For Information Presentation. Pervasive Computing, vol. 16. (pp.14-22) Washington, DC: IEEE CS.

de Souza e Silva, A. \& Frith, J. (2012). Mobile Interfaces in Public Spaces. New York, NY: Routledge.

Eberhard, J. (2009). Applying Neuroscience to Architecture. Neuron 6. (pp.753-756). Cell Press.

Farahi, B. (2013). Alloplastic Architecture: The Design of an Interactive Tensegrity Structure". Presentation, ACADIA Conference, University of Waterloo, Cambridge, Ontario, October 24-27, 2013.

Fox, M. \& Kemp, M. (2009). Interactive Architecture. New York, NY: Princeton Architectural Press.

Glynn, R. 2016. Foreword. In Fox, Interactive Architecture 2 -Adaptive World, 2016 (pp.1-2). 
New York, NY: Princeton Architectural Press.

Greenfield, A. (2006). Everyware: The dawning age of ubiquitous computing. Berkeley, CA: New Riders.

Haeusler, H. (2009). Media Facades: History, Technology, Content. Ludwigsburg, DE: Avedition.

Haeusler, H. (2010). Chromatophoric architecture:designing for 3D media façades. Berlin: Jovis.

Halskov, A. \& Ebsen, T. (2013). A framework for designing complex media facades. Design Studies Vol. 34. (pp.663-679).

Haque, U. (2006). Architecture, Interactions, Systems. AU: Arquitetura \& Urbanismo 149.

Hespanhol, L., Haeusler, H., Tomitsch, M. And Tscherteu, G. (2017). Media architecture compendium : digital placemaking. Stuttgart, DE: Avedition.

Hoelzel, I. \& Marie, R. (2016). Brave New City: the image in the urban data-space. Visual Communication, Vol 15(3). Sage. DOI 10.1177/1470357216642638

Horowitz, A. C., \& Bekoff, M. (2007). Naturalizing Anthropomorphism: Behavioral Prompts to Our Humanizing of Animals. Anthrozoös, 20(1). (pp.23-35). doi:10.2752/089279307780216650

Jansen, K., Dragicevic, P., Isenberg, P., Alexander J., Karnik A., et al. (2015). Opportunities and Challenges for Data Physicalization. Proceedings of the ACM Conference on Human Factors in Computing Systems (CHI), Apr 2015, New York, NY, United States.

Kuniavsky, M. (2010). Smart Things: Ubiquitous Computing User Experience Design. Burlington, MA: Morgan Kaufmann.

Manovich, L. (2006). The poetics of augmented space. Visual Communication, 5(2), 219-240. doi:10.1177/1470357206065527

O'Neill, J. (1985). Five Bodies: The Human Shape of Modern Society. Ithica, NY: Cornell University Press.

Park, J.W. (2013). Interactive Kinetic Media Facades: A pedagogical Design System to Support an Integrated Virtual Physical Prototyping Environment in the Design Process of Media Facades. Seoul: Global School of Media.

Shannon C. And Weaver W. (1949). The Mathematical Theory of Communication. Champaign, Il: University of Illinois Press.

Stojsic, M. (2017). (New)MediaFacades:Architecture and/as a Medium in Urban Context. Am Journal 12. (pp.135-148).

Tomkins, S. (1962). Affect Imagery Consciousness. Vol I: The Positive Affects New York: 


\section{Springer.}

Tuan, Y. (1977). Space and Place: The perspective of experience. Minneapolis: University of Minnesota Press.

Tomitsch, A., Vande Moere, A. \& Grechenig, T. (2008). Framework for Architecture as a Medium for Expression. Pervasive 2008. Sydney.

Vande Moere, A. (2008). Beyond the Tyranny of the Pixel: Exploring the Physicality of Information Visualization. In $I V^{\prime} 08$ Proceedings of the 2008 12th International Conference Information Visualisation. 2008 (pp. 469-474). Washington: IEEE Computer Society.

Vande Moere, A. \& Wouters, N. (2012). The Role of Context in Media Architecture. In proceedings of PerDis 2012. Porto, Portugal.

Wiener, N. (1948). Cybernetics: Or Control and Communication in the Animal and the Machine. Cambridge, MA: MIT Press.

Willett, W., Jansen, Y. And Dragicevic, P. (2017). Embedded Data Representations. In IEEE Transactions on Visualization and Computer Graphics, Institute of Electrical and Electronics Engineers, 2017. (pp.461 - 470). 